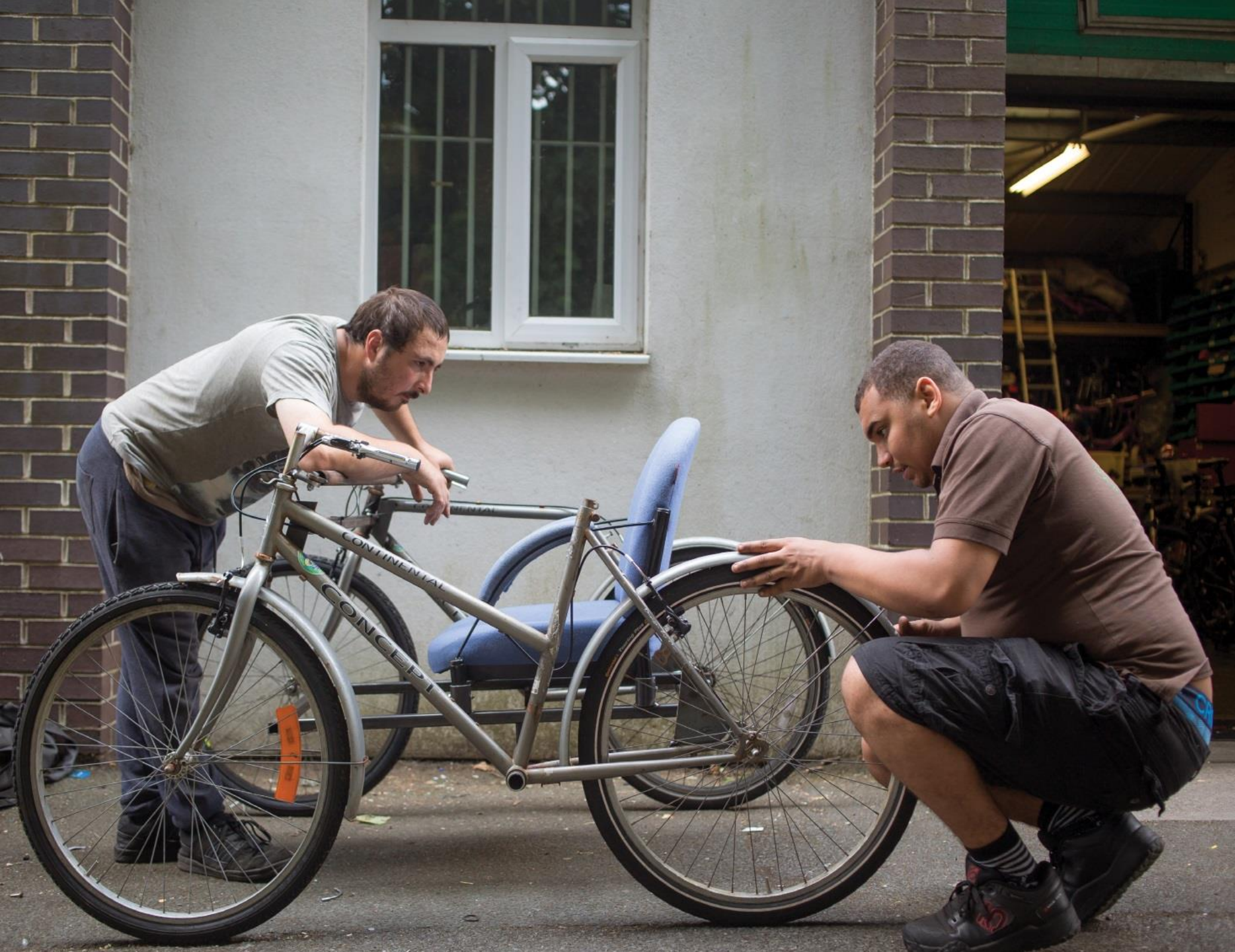





\section{Talent Match Evaluation: Progression to Employment}

Authors

Richard Crisp

Chris Damm

Anne Green

Sarah Pearson

Elizabeth Sanderson

Peter Wells

For further details contact Professor Peter Wells (Evaluation Director) at p.wells@shu.ac.uk / 01142253073

October 2018

DOI: 10.7190/cresr.2018.3322694645 


\section{Acknowledgements}

We are extremely grateful to all those who have helped in the course of the evaluation. We are particularly grateful to the staff, young people and board members of the 21 Talent Match partnerships who have given their time freely to support the evaluation. A particular mention should be made of partnership leads and those involved in setting up the Common Data Framework (CDF). We trust that in time the considerable benefits of the CDF will be seen in terms of contributing to a robust evidence base on which to design future policies and programmes.

A wide range of staff and committee members at the Big Lottery Fund have helped, supported and advised upon the evaluation. Their time has been invaluable. We are particularly grateful to Jolanta Astle, Sarah Cheshire, James Godsal, Scott Hignett, Scott Highland, Matt Poole and Roger Winhall. We are also grateful to former Big Lottery Fund colleagues Linzi Cooke and Scott Greenhalgh who provided invaluable assistance at the start of the Talent Match Evaluation.

Lastly, we would like to thank the evaluation team at Sheffield Hallam University, the University of Birmingham, the University of Warwick and Cambridge Economic Associates: Duncan Adam, Gaby Atfield, Dr Sally-Anne Barnes, Nadia Bashir, Dr Richard Crisp, Dr Chris Damm, Dr Maria de Hoyos, Dr Will Eadson, Professor Del Roy Fletcher, Dr Tony Gore, Professor Anne Green, David Leather, Elizabeth Sanderson, Emma Smith, Louise South, Professor Pete Tyler, Sarah Ward and lan Wilson. We would also like to thank our former colleague Ryan Powell who supported the original evaluation design.

Peter Wells (Evaluation Director) and Sarah Pearson (Evaluation Project Manager) 


\section{Contents}

\section{Summary}

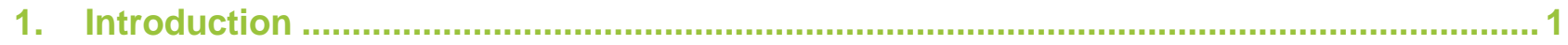

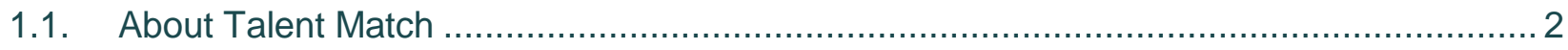

1.2. Targeting and Progression and the Talent Match programme …................................ 2

2. Understanding place-based and people-based targeting ................................. 4

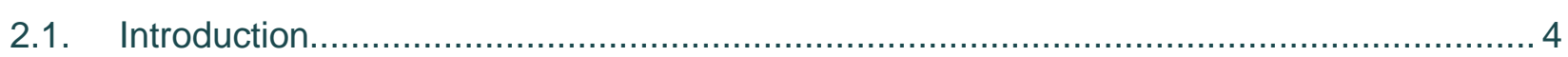

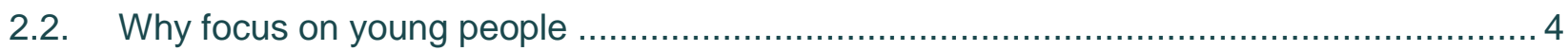

2.3. Which young people do young people employability programmes target? ..................... 7

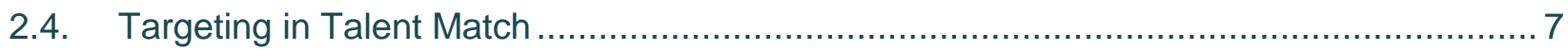

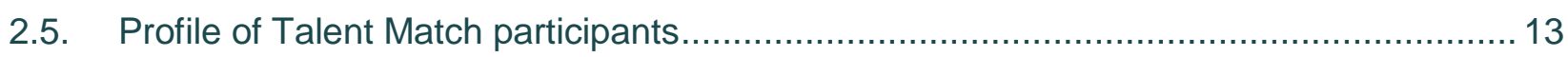

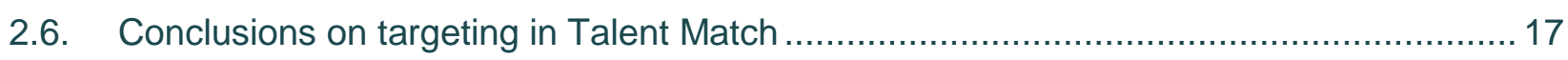

3. Understanding progression towards, into and within employment...................... 19

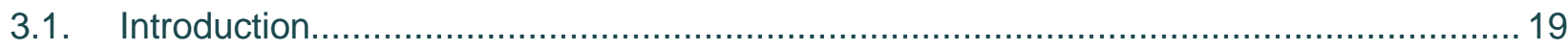

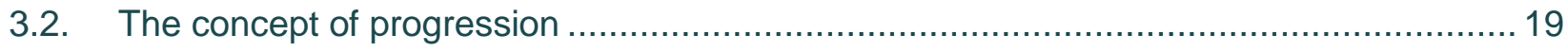

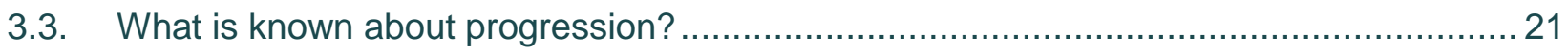

3.4. Findings from Talent Match quantitative analyses ............................................ 23

3.5. Findings from Talent Match longitudinal qualitative data analyses ............................. 30

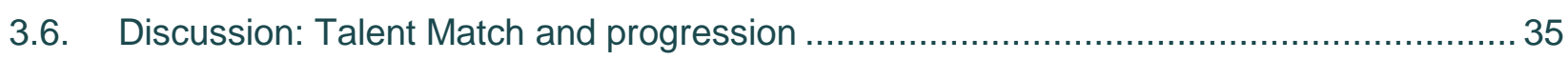

4. Conclusions

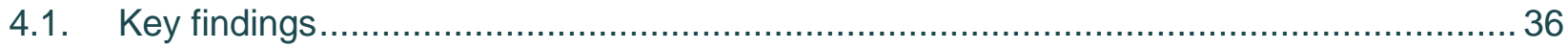

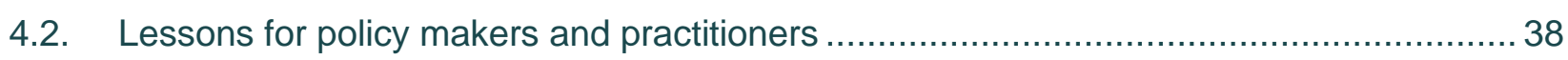





\section{Summary}

This report draws together evidence on understanding the local areas and sub-groups of young people that the Talent Match programme has focused on and their progression into and within employment, as well as more broadly in terms of confidence and well-being.

\section{About Talent Match}

Talent Match is an innovative programme designed to address unemployment amongst 1824 year olds. It is being delivered using National Lottery funding between 2014 and 2018 through partnerships in 21 Local Enterprise Partnership (LEP) areas in England. The programme seeks to support young people who are furthest from the labour market through personalised, non-standardised provision which addresses their needs and aspirations. Participation in the programme is voluntary. Talent Match has been co-designed by and is co-delivered with young people.

\section{Targeting on local areas and sub-groups of young people in Talent Match}

Unemployment increases at times of recession tend to be higher than average for young people. The original focus of the Talent Match programme was on geographic hotspots of youth unemployment. How this was interpreted varied, although most Talent Match partnerships had some place-based (i.e. spatial) targeting at the outset. Over time placebased targeting became more relaxed in most partnerships. Most Talent Match participants came from relatively deprived areas.

Sub-groups of young people targeted varied across Talent Match partnerships, but there was considerable similarity in the main target groups. All partnerships targeted the long-term unemployed and emphasised helping the 'hidden unemployed'. Talent Match had a strong emphasis on helping young people with mental health issues.

\section{Progression towards, into and within employment and enhanced well-being}

Monitoring statistics show how young people progressed on the Talent Match programme. Two in five Talent Match participants (41 per cent) entered employment and nearly one in five employees (18 per cent) sustained employment for at least six months. Those with good formal qualifications were more likely, and those with disabilities were less likely, to achieve these outcomes. Nearly half of young people participating in Talent Match (46 per cent) undertook a work placement or volunteering opportunity. These are important mechanisms for supporting progression of those Talent Match participants facing considerable challenges to labour market participation. Around three in four Talent Match participants (78 per cent) who initially recorded a low well-being score went on to record a higher well-being score at a later stage. While not all positive outcomes for Talent Match participants can be directly attributed to the Talent Match programme, especially for young people with access to other positive support networks, most Talent Match participants acknowledged that the support that they had received through Talent Match partnerships was helpful in supporting them to progress toward their employment goals. 
Self-defined progress varied across Talent Match participants with some making 'significant progress' against clear employment goals, others making 'reasonable progress' and some 'limited or no' progress. Overall, the balance of evidence indicates that Talent Match acted as a catalyst for progress towards employment by causing or accelerating positive change in many cases.

\section{Lessons}

- Talent Match has made an important contribution to young people's progression: While not all positive outcomes for Talent Match participants can be directly attributed to the Talent Match programme, especially for young people with access to other positive support networks, most Talent Match participants acknowledged that the support that they had received through Talent Match partnerships was helpful in supporting them to progress toward their employment goals.

- Support for both work-related and non-work issues is needed to support young people to progress: A key part of the 'Talent Match journey' is about improved wellbeing. Evidence points to the positive impacts of an integrated package of support (which includes key worker support) in helping individuals enter, sustain and progress in work. However this support can be expensive, especially for individuals who are furthest from the labour market.

- Employers have an important role in progression: Employability programmes are often criticised for their supply-side emphasis (e.g. on the unemployed and not on employers). In any employment programme it is important to remember the role of the employer, since it is employers who are gatekeepers of jobs. For progression into employment to be achieved understanding employers' requirements and working with them, as appropriate, to support programme participants in work is beneficial. Talent Match thematic research on in-work support has provided some good examples of working with employers to secure progression.

- Progression is also influenced by the quality of jobs available and young people's understanding employment options. The self-assessment of young people regarding the progress that they had made highlights how some felt thwarted by unfulfilling jobs. While very few secure their dream job at the outset, the Talent Match evidence suggests that the quality of jobs is important for well-being and in terms of opportunities for progression. This highlights the importance of attempting to match jobs with individuals' aspirations, while also using programme support to develop an understanding of alternative job opportunities thematic research on key workers and the role of high quality information, advice and guidance shows how this might be done. 


\section{Introduction}

Typically, employment programmes and policy interventions focus on particular target groups of the population with specific characteristics or living in particular local areas. Their objective is to enable programme participants to improve their position by making progress towards and within employment.

This report synthesises evidence on targeting and progression in the Talent Match programme. Targeting refers to the local areas and groups of people where Talent Match resources and activity were specifically focused. Progression refers to movement towards and into employment and advancement within employment towards better jobs. Its purpose is to present evidence from the Talent Match programme on targeting and progression and to assess the findings in the context of the broader evidence based on these topics. The report is intended for audiences interested in the implementation of employability programmes and in 'what works' regarding positive transitions for young people and more particularly progression into and within work.

First, the report reviews evidence on targeting, it starts with a discussion on why employment programmes focus on young people before considering in more detail the approaches to place-based (i.e. spatial) and people-based (i.e. sub-group) targeting in the Talent Match programme and the profile of Talent Match participants. It then moves on to consider progression, starting with a discussion of the concept of progression and the associated evidence base. Findings from quantitative, qualitative longitudinal and thematic studies are presented. The final section concludes with key findings and lessons from the Talent Match programme on targeting and progression.

The report draws on a range of data sources:

- An annual programme of visits to Talent Match partnerships carried out between 2014 and 2016 and involving face-to-face interviews with partnership leads, strategic partners, delivery partners and young people.

- Surveys of lead partner organisations and delivery organisations conducted in 2014, 2015 and 2018.

- Monitoring and administrative information collected by the Big Lottery Fund (the Fund).

- Initial project plans submitted by Talent Match partnerships.

- Engagement with Talent Match partnerships through events and workshops which have explored a range of aspects of Talent Match provision. 
- Data on the characteristics, progress and outcomes of programme participants collected through a through a Common Data Framework (CDF) ${ }^{1}$ and broader quantitative analysis based on secondary data sources and administrative statistics.

- Interviews with young people participating in the Talent Match programme: semistructured interviews with Talent Match participants were conducted in two waves between 2015 and 2017. A total of 61 interviews were carried out in wave 1, and 66 interviews in wave 2. Fifty seven percent of interviewees who participated at wave 1 were also interviewed at wave $2(n=35)$.

- Thematic case studies of the involvement of in-work support in Talent Match, ${ }^{2}$ the role of key workers, ${ }^{3}$ and employer involvement and engagement. ${ }^{4}$

\subsection{About Talent Match}

The Fund has invested £106 million in Talent Match, an innovative programme designed to address unemployment amongst 18-24 year olds. It is being delivered using National Lottery funding between 2014 and 2018 through voluntary and community sector (VCS) led partnerships in 21 Local Enterprise Partnership (LEP) areas in England. The programme seeks to support young people who are furthest from the labour market through personalised, non-standardised provision which addresses the needs and aspirations of young people.

Participation in the programme is voluntary, and a key innovation of Talent Match is that it has been co-designed by and is co-delivered with young people. This sets it apart from previous youth employment initiatives and current government employment programmes.

The Talent Match programme is being evaluated by a consortium of partners led by the Centre for Regional Economic and Social Research (CRESR) at Sheffield Hallam University working with the Warwick Institute for Employment Research at the University of Warwick, City-REDI (Regional Economic Development Institute) at the University of Birmingham and Cambridge Economic Associates. The evaluation runs from 2013 until 2019.

\subsection{Targeting and Progression and the Talent Match programme}

Terms such as 'targeting' and 'progression' are sometimes used rather loosely, so it is appropriate at the outset to outline how they are interpreted in this report.

Targeting is about the local areas and sub-groups that the Talent Match programme was focused on. The emphasis here is on place-based and sub-group targeting (i.e. selection of the local areas and sub-groups of young people which were the focus of

\footnotetext{
${ }^{1}$ Including Damm, C. and Sanderson, E. (2018) Personal characteristics and outcomes: who benefits from the Talent Match programme. Sheffield: CRESR, Sheffield Hallam University (unpublished report).

${ }^{2}$ Green, A., Barnes, S-A., Gore, T. and Damm, C. (2017) In-work support: What Is the role of in-work support in a successful transition to employment?, Talent Match Case Study Theme Report. Sheffield Hallam University, University of Warwick, Big Lottery Fund. https://www4.shu.ac.uk/research/cresr/sites/shu.ac.uk/files/tm-in-worksupport-report.pdf

${ }^{3}$ Barnes, S-A., Green, A., Batty, E. and Pearson, S. (2017) Key worker models: What key worker approaches, capacity and capability are important at different stages of the journey to employment?, Talent Match Case Study Theme Report. Sheffield Hallam University, University of Warwick, Big Lottery Fund. https://blogs.shu.ac.uk/talentmatch/files/2015/03/tm-key-worker-report.pdf

${ }^{4}$ Green, A., Atfield, G. and Barnes, S-A. (2015) Employer involvement and engagement, Talent Match Case Study Theme Report. Sheffield Hallam University, University of Warwick, Big Lottery Fund. https://www4.shu.ac.uk/research/cresr/sites/shu.ac.uk/files/tm-employer-involvement-engagement-2015.pdf
} 
Talent Match activities). Key issues include whether the programme reached the individuals it was designed to target and whether, how and why targeting changed over time.

Given that Talent Match is an employment programme, progression focuses specifically on entry to, sustaining and progression in employment. However as Talent Match also addressed broader needs and aspirations of young people reference is also made to whether and how Talent Match contributed to broader outcomes including enhanced confidence and well-being. 


\section{Understanding place-based and people-based targeting}

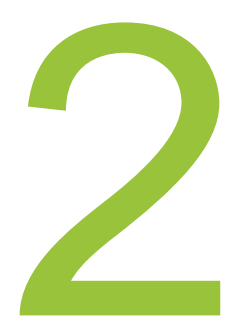

\subsection{Introduction}

This section outlines the rationale for employability programmes to focus on young people, specifically those young people facing challenges in entering and sustaining employment. It then moves on to discuss targeting in the Talent Match programme, with a particular focus on which local areas and sub-groups of young people the Talent Match partnerships focused on. Finally the profile of Talent Match participants is explored.

\subsection{Why focus on young people}

With the so-called 'Great Recession' there was a sharp rise in unemployment in the UK. As in previous recessions youth unemployment increased more rapidly than the overall level of unemployment. Youth unemployment reached a peak in 2011. Part of the rise in youth unemployment in this latest recession reflects the greater sensitivity of youth unemployment than general unemployment to the economic cycle. High levels of unemployment generally lead to greater competition amongst job seekers and young people may be vulnerable because of their lack of work experience.

Importantly, there were signs that the relative position of young people in the labour market was deteriorating prior to 2008, suggesting that high levels of youth unemployment are not solely a consequence of recession, albeit they are exacerbated by it. Rather, the root cause goes beyond the state of the economy to underlying structural issues in the youth labour market. ${ }^{5}$ The labour market for young people started to worsen in the 1970s. Then young people were badly hit by the early 1980s recession. The relative labour market performance of young people continued to decline thereafter in the remainder of the 1980s and for part of the 1990s. In part this deteriorating position can be explained by the fact that the sorts of jobs that young people, particularly non-graduates, used to go into have been declining and those that are left are increasingly contested by older and more experienced workers. ${ }^{6}$

There has been a significant fall in youth unemployment since 2011 - and this has implications for targeting, but the unemployment rate for young people remains higher than that across all age groups. There are recent signs those reductions in

\footnotetext{
${ }^{5}$ House of Lords European Union Committee (2014) Youth unemployment in the EU: a scarred generation? 12th Report of Session 2013-14, HL Paper 164. London: The Stationery Office.

${ }^{6}$ UKCES (2014) Precarious futures? Youth unemployment in an international context. Wath-upon-Dearne and London: UK Commission for Employment and Skills.
} 
unemployment are faltering, with the Learning and Work Institute commenting in February 2018 that: "The growth in unemployment has been concentrated among young people, with a quarterly rise of 66,000 unemployed under six months, suggesting a weakening youth labour market."7 According to the Impetus-PEF Youth Jobs Index $2017^{8}$ the number of young people spending 12 months or more unemployed was 811,000 - up from 714,000 the previous year - suggesting that a structural problem remains.

There is also an ongoing concern about the numbers of young people who are unemployed but not claiming benefit. In written evidence presented in September 2016 to the House of Commons Work and Pensions Committee's Enquiry on 'Employment Opportunities for Young People' ${ }^{9}$ the Learning and Work Institute estimated that the proportion of unemployed young people (not counting students) not claiming Jobseeker's Allowance, and therefore not receiving official help with job search, was 59.7 per cent, having risen by more than thirty percentage points since October 2012. In early 2018 the estimated proportion of unemployed young people in this category remained high at 54.6 per cent. ${ }^{10}$ This may reflect changes in welfare conditionality, such as the use of benefit sanctions, and is of importance given that the 'hidden unemployed' are a key target group for Talent Match.

There are also concerns about the position of young people in employment, especially regarding the 'low pay no pay' cycle which persists for those young people (often with low or no qualifications) who are moving in and out of unstable employment ${ }^{11}$ - with implications for progression. Those young people in employment are more likely to be working part-time, more likely to be in temporary employment and more likely to be on zero-hours contracts than older workers. ${ }^{12}$ While some people might choose to work in these ways it remains the case that such working arrangements are precarious for others. In part this reflects features of the sectors in which young people are employed. There have been marked changes in the sectoral profile of youth employment since the 1980s, reflecting shifts that have affected everyone, with a decrease in employment of young people in manufacturing and increases in sectors such as distribution, hotels and restaurants. ${ }^{13}$

Furthermore, evidence suggests that in recent years a number of factors, including an increase in the number of small businesses with limited resources, have resulted in a move towards the expectation by employers that young people should be 'work ready' rather than trained 'on the job'. ${ }^{14}$ This disadvantages young people and suggests that so-called 'soft skills' and work experience are becoming especially vital for young people in order to gain first employment as a precursor to sustained employment.

\footnotetext{
7 Learning and Work Institute comment on February 2018 unemployment statistics - see https://www2.learningandwork.org.uk/statistics/labour/february-2018

${ }^{8}$ Impetus-PEF Youth Jobs Index August 2017

${ }^{9}$ House of Commons Work and Pensions Committee (2017) Employment Opportunities for Young People, HC 586 (https://publications.parliament.uk/pa/cm201617/cmselect/cmworpen/586/586.pdf)

${ }^{10}$ In the latest estimate published by the Learning and Work Institute in February 2018 it is estimated that: "the proportion of unemployed young people (not counting students) who are not claiming Jobseeker's Allowance and therefore are not receiving official help with job search is now 54.6\%" (from https://www2.learningandwork.org.uk/statistics/labour/february-2018)

${ }^{11}$ Shildrick, T., MacDonald, R., Webster, C., and Garthwaite, K. (2012) Poverty and Insecurity: Life in low-pay, no-pay Britain. Bristol: Policy Press.

12 Green, A. and Wells, P. (2018) Talent Match Evaluation and Learning Contract 2013-19: Policy Review. Sheffield: CRESR, Sheffield Hallam University.

${ }^{13}$ Sissons, P. and Jones, K. (2012) Lost in transition? The changing labour market and young people not in employment, education or training. London: The Work Foundation.

${ }^{14}$ House of Lords European Union Committee (2014) op cit.
} 
The sensitivity of youth unemployment to the economic cycle, underlying structural issues in the youth labour market, concerns about 'hidden unemployment', the precarious nature of employment for some young people (especially those with no/ low qualifications) and a requirement from employers for young people to be 'work ready' mark out young people as prime candidates for policy focus. There is compelling evidence of the scarring effects on life-time income and life prospects for people experiencing periods of youth unemployment, and this translates into costs for the state and wider society. ${ }^{15}$ Talent Match is concerned with reducing these lifetime effects on individuals, as well as other broader costs.

Given the trends and concerns noted above, it is not surprising that young people have been a key focus of employability programmes since the late 1970s and through the 1980s. Examples include the Youth Opportunities Programme, the Youth Training Scheme, the Young Workers Scheme and the New Workers Scheme. Under the New Labour Government in 1998 the New Deal for Young People, a compulsory active labour market programme, was introduced as the flagship of the UK Labour Government's New Deal policies. It involved an initial Gateway period in which New Deal advisors worked with the young person to improve their employability and to find unsubsidised jobs. For those young people not finding jobs this was followed by either a six-month period of subsidised employment, a course of full-time education and training, a job in the voluntary sector or a job in the Environmental Task Force. These schemes took a supply-side focus.

The rise in unemployment in the 'Great Recession' saw renewed interest in employability programmes targeted primarily at young people, including the Future Jobs Fund. Talent Match also dates from this period. The Work Programme was introduced in 2011 and consolidated support for the long-term unemployed including young people - on a mandatory basis. The Youth Contract was launched in 2012 with the aim of helping young unemployed people prepare for work and find long-term employment. It included funding for 'wage incentives' for employers who recruit 18-24 year olds who have spent six months or more on benefits and subsidies for small businesses taking on young apprentices.

More recent developments include the roll-out of Universal Credit (replacing Jobseekers Allowance and Employment Support Allowance, as well as a number of other benefits), and the introduction of a new Youth Obligation from 2017 requiring all Universal Credit claimants aged 18-24 to either 'earn or learn', plus a new Intensive Activity Programme for new claimants. The Work and Health Programme replaced the Work Programme in 2017/18. It is voluntary for people with health conditions and disabilities but compulsory for those unemployed over two years (including young people).

Alongside national policies focusing on young people there have been a range of local initiatives focusing on tackling youth unemployment and improving young people's employability. Hence Talent Match has been focusing on young people at the same time as national active labour market policies and local initiatives.

Policies to promote youth employability have also focused on promoting education and training. Initiatives have included raising the participation age, greater emphasis on achieving good Maths and English qualifications (at GCSE level), funding of 18-24 year olds to get their first level 2 or 3 qualification, and increasing the number of apprenticeships, traineeships and sector-based work academies

${ }^{15}$ Gregg, P. and Tominey, P. (2005) The wage scar from youth unemployment. Labour Economics, 12, pp. 487509; Bell, D. and Blanchflower, D. (2011) Young people and the Great Recession. Oxford Review of Economic Policy, 27, pp. 241-267. 
(providing pre-employment training, qualifications, and work experience), so providing route ways to jobs.

\subsection{Which young people do young people employability programmes target?}

In general the employability programmes outlined above have used long duration unemployment as the key criterion for targeting, although it has been recognised that some categories of young people - including those with disabilities, those who are care leavers, those with criminal records, and those with no/low skills, etc. - are particularly vulnerable to unemployment and so in some programmes have been afforded early entry to the support provided. As noted in the following section on subgroup targeting, the Talent Match programme has tended to target particular subgroups, although the approaches to targeting have varied to some extent by Talent Match partnerships.

Headline analyses of the profile of Talent Match participants are presented below, including a comparison with all NEETs (not in employment, education or training) in the same age group.

\subsection{Targeting in Talent Match}

Having set the context, this section provides evidence on place-based (i.e. spatial) and people-based (i.e. sub-group) targeting in the Talent Match programme, making reference to differences between Talent Match partnerships. Given that partnerships identified key local needs - in terms of socio-economic and demographic groups, different causal factors leading to worklessness and where geographic concentrations of need were located - approaches to targeting would be expected to vary to some extent. It is also notable that over the lifetime of the Talent Match programme the number of (long-term) unemployed young people decreased quite considerably and it would be expected that this reduction would have implications for targeting strategies.

\section{Place-based targeting}

Talent Match partnerships were built at Local Enterprise Partnership (LEP) level. The programme is targeted on areas with concentrations of young people who have been out of employment, education or training (i.e. NEET) for 12 months or more. These areas were identified through a sequential analysis, as follows:

1. Identification of LEP areas with the highest percentage of 18-24 year olds who had been out of work for 12 months.

2. Within each area, the Big Lottery Fund examined the 2010 NEET count, where it was available, to identify so-called 'hotspot' areas of youth unemployment.

3. In each area, the Big Lottery Fund considered the opportunities existing for enterprise and employment growth, which could potentially provide vacancies suitable for young people who benefit from the funded approaches.

4. The Big Lottery Fund considered a range of geographical characteristics, such as rural or urban, coastal or inland, to make sure the selected areas offered a breadth of approaches from which to gather learning.

An important aspect of the Talent Match programme as envisaged at the outset was a focus on geographic 'hotspots' of youth unemployment. In the initial stages of the Talent Match programme it was assumed that partnerships would be targeting participants by geography or by need/theme or a combination of both, and this was a 
feature of original partnership plans. It was envisaged that partnerships would identify specific areas within the LEP area where there were high proportions of NEET young people aged 18-24. These areas would be the 'hotspots' and, crucially, local eligibility for the Talent Match programme would be restricted largely to individuals from those areas.

It became clear early in the lifetime of the programme that different approaches to place-based targeting were being taken, as well as the targeting of groups rather than areas. The difference in approaches to this issue is not surprising given the fact that early interviews with partnership contacts uncovered some ambiguity as to whether or not identification of hotspots and/or targeting resources on these areas was a requirement of Talent Match funding. In some cases this meant that placebased targeting was not a high priority. As one partnership lead asserted:

\section{The point about hidden NEETs is that they are across the board - they are not just focused in one area. (Partnership lead)}

Most partnerships used some form of place-based targeting (at least at the outset), although this varied widely from quite small areas (including some nonstandard areas) to whole districts. Approaches included:

- Identification of hotspots and subsequent use as an eligibility criterion for participation in the Talent Match programme.

- Identification of hotspots to inform delivery activity, but without use as an eligibility criterion.

- No identification of hotspots but nevertheless there was an intention to target certain areas - albeit the definitions of these areas were vague and relied on a common understanding of localities rather than on statistical units.

In theory this state of affairs provided an opportunity to test and learn from different approaches to place-based targeting and how they work in particular contexts. However, in practice a stronger rationale and guidance on targeting would have been helpful at the outset. For a programme seeking to support innovation and based on a 'test and learn' approach, there needs to be a clearer case made for why particular areas (and groups) are being supported.

Early in the life of the Talent Match programme the 21 Talent Match partnerships were classified into five groups on the basis of the specific nature of their placebased targeting approach: ${ }^{16}$

1. Defined place-based targeting on specific wards (10 partnerships) - This represents the anticipated approach given the focus on hidden NEETs and geographical hotspots. Although this represents the most common approach, only half of the partnerships fall into this group.

2. Specific estates within specific targeted wards are identified (1 partnership) This may be considered a variation of category 1 .

3. A mix of whole local authority districts (within undefined 'hotspots') and other local authority districts with hotspots defined (2 partnerships) - In one instance this approach was reported to have stemmed from the views expressed by young people at the design stage.

4. A focus on undisclosed parts or across all parts of local authority districts (7 partnerships) - This is the second most common approach. In a number of

\footnotetext{
${ }^{16}$ This was done in part to compile labour market information for relevant geographies.
} 
Talent Match partnerships 'hubs' are identified but there is no focus on a specified and bounded geographic area. (This approach is more common in sparsely populated rural areas, though not exclusive to them).

5. A strong thematic approach (1 partnership) - In this instance it was difficult to ascertain the approach to place-based targeting since prominence was given to delivering across areas with a thematic rather than geographic focus.

This highlights that from the outset Talent Match partnerships were on a continuum regarding the specificity of place-based targeting and on whether it would be used as an eligibility criterion. It is notable that evidence from interviews with partnership leads and young people involved in the design and development of projects suggests that nearly all partnerships would not turn away potential participants irrespective of place of residence.

Interviews conducted during partnership visits sometimes revealed a difference of views about place-based targeting. For example, in the Greater Lincolnshire Talent Match partnership, where there was quite strict place-based targeting at the outset focusing on a small number of pre-defined wards, one view was that it was appropriate to "stick with it" for as long as possible to test whether a geographical concentration of resources in the target areas would have an impact, whereas another view was that this was "unfair" to people living outside those wards.

In the Leicester and Leicestershire Talent Match partnership the original approach was one of place-based targeting focusing on specific wards. Over time there were strong pressures to relax the place-based targeting for a mix of practical and more ideological reasons:

- A reduction in numbers on Jobseekers Allowance.

- Demand for Talent Match-type services outside the target wards.

- A belief amongst some interviewees that some organisations do not make referrals to initiatives where eligibility is defined by postcodes.

- That it was not fair to deny access to support services to some people on a voluntary programme on the basis of residential location; (young people, in particular, tended to be opposed to a 'postcode lottery' of different service provision in different areas, and so played an influential role in relaxing placebased targeting).

In this particular case a decision was made to relax geographical targets - first allowing 20 per cent of referrals to come from other areas and subsequently by extending outreach activities to other deprived estates within the city.

In some other Talent Match partnerships where place-based targeting was somewhat less pronounced at the outset there was also an expansion of the geographical areas (within the LEP area) where young people were recruited from. For example, in the Coventry and Warwickshire Talent Match partnership interviews the rationale given for extending place-based targeting beyond the original emphasis on areas with highest unemployment was two-fold:

- A lot of enquiries to Talent Match were from people outside the original target areas and the Talent Match partnership did not want to turn them away.

- With a reduction in unemployment there was a concern that Talent Match would not be able to recruit enough young people from the areas initially targeted. 
A final example of relaxing place-based targeting over time is provided by the D2N2 (Derby City, Derbyshire, Nottingham City and Nottinghamshire) Talent Match partnership. Initially, services were delivered from four hubs - one in each of the four areas. In Year 1 the geographical focus was on 28 wards with high levels of youth unemployment. This was extended to 95 wards (by including the whole of some smaller towns and clusters of wards in Year 2). There was also a target of $20 \%$ of referrals from outside ward clusters. The rationale given in partnership visit interviews for relaxation of place-based targeting was that it was unpopular with, and posed difficulties for, referral and delivery agencies and with young people because of uncertainty about who was eligible for Talent Match. The revised approach was deemed more inclusive and was reported to have reduced frustration about eligibility for Talent Match on the basis of tightly defined postcodes. The delivery network was expanded accordingly, with the establishment of more delivery hubs.

Regardless of the nature of any place-based targeting approach adopted, Figure 2.1 shows that in practice most Talent Match participants live in relatively deprived neighbourhoods, including nearly two in five from the 10 per cent most disadvantaged areas in England and three in five from the 20 per cent most disadvantaged areas in England as measured by the Index of Multiple Deprivation. ${ }^{17}$

Figure 2.1: Percentage of Talent Match participants by level of deprivation in neighbourhood of residence

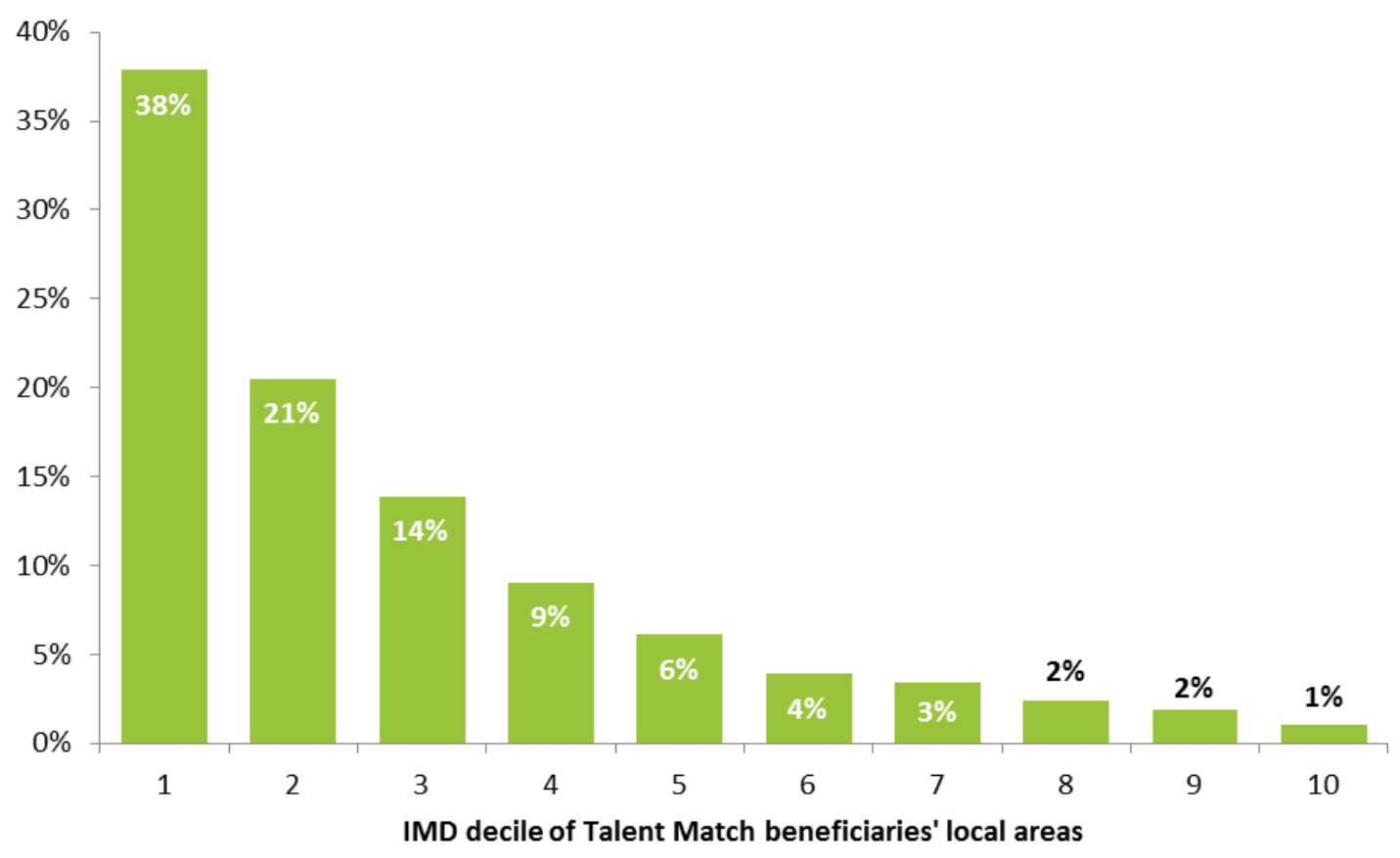

Source: Baseline survey (23,510), 2015 IMD data.

Note: IMD (Index of Multiple Deprivation) decile 1 denotes the 10 per cent most deprived neighbourhoods in England and IMD decile 10 denotes the 10 per cent least deprived neighbourhoods in England.

17 This is a ranking of all neighbourhoods in England according to the 2015 Index of Multiple Deprivation published by the Department of Communities and Local Government. 
In summary:

- There was some ambiguity at the outset regarding requirements for place-based targeting.

- Approaches to place-based targeting varied across Talent Match partnerships.

- There were some strong views that place-based targeting was inappropriate on the grounds that it was not inclusive.

- Over time (and from early in the Talent Match programme) place-based targeting became more relaxed.

- The majority of Talent Match participants were from relatively deprived neighbourhoods.

\section{Sub-group targeting}

Targeting of those furthest from the labour market and providing them with holistic support was part of the rationale for the Talent Match programme. Precisely which sub-groups of young people were highlighted for targeting at the outset varied by area and by particular needs in specific localities. Typically sub-groups specifically targeted by partnerships consisted of a combination of the following (which are not mutually exclusive): young people not in education, employment or training (NEETs); long-term unemployed; offenders; care leavers; lone parents; young parents; people with physical disabilities; people with learning disabilities; people suffering from mental ill health; carers; homeless people; Black and Minority Ethnic groups; refugees/ asylum seekers; gypsies and travellers; people engaged in alcohol and/or substance misuse; people with low levels of literacy and numeracy problems and people with low confidence levels.

In some Talent Match partnerships analyses of Talent Match Project Plan documents and Talent Match partnership data validation reveals that the sub-groups selected for targeting were quite specific - for example:

- Greater Manchester: lone parents, carers, alcohol and substance misusers, exoffenders, care leavers, those with health related issues.

- Humber: ex-offenders, Black and minority ethnic groups, gypsies and travellers, lone parents, young carers, those with physical disabilities, those with learning disabilities, and those with mental health related issues.

Figure 2.2 shows the number of partnerships targeting different sub-groups according to Partnership Survey data. All Talent Match partnerships responding targeted the long-term unemployed and the majority also placed a particular focus on people with mental health issues. A sizeable number of partnerships targeted young and/or lone parents. 
Figure 2.2: Sub-groups targeted

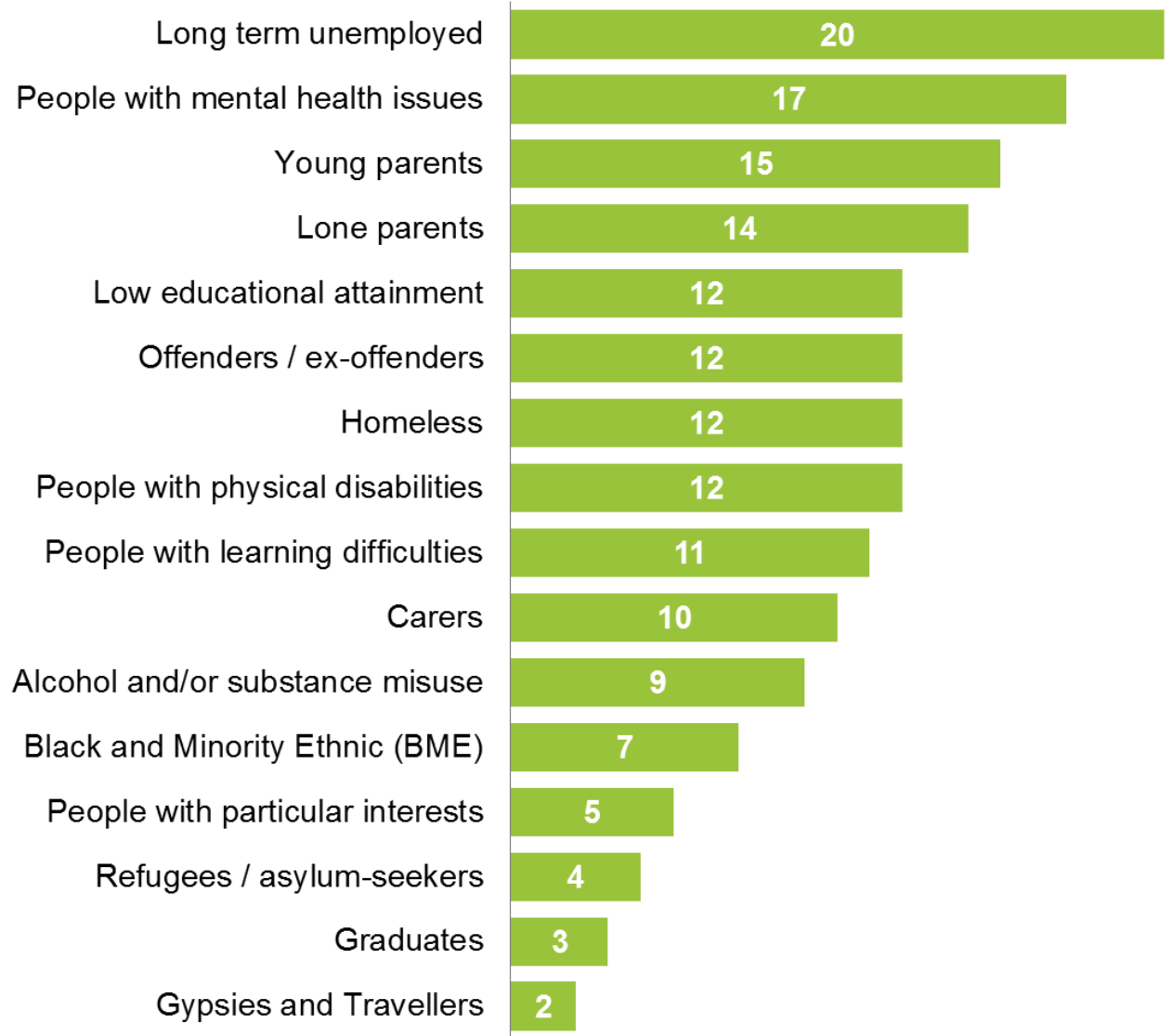

Base: 20

Source: Partnership Survey 2018

Some Talent Match partnerships included in their target groups young people facing particular circumstances/ contexts. For example, in the Coventry and Warwickshire Talent Match partnership one of the initial target groups was 'Young people facing cultural and/or generational barriers (e.g. third generation unemployed families, young people in North Warwickshire who have never been out of their home town'. In The Marches one of the target groups was 'those leading chaotic and unstructured lifestyles, those who are risk taking, those who prefer not to register their existence officially'.

In partnership visits interviewees placed particular emphasis on recruiting the 'hidden unemployed' to the Talent Match programme. In some Talent Match partnership areas (including London, Leicester and Leicestershire, Tees Valley, New Anglia, Cornwall, The Marches) 'hidden' young people/ NEETs were specifically mentioned as a target group.

All partnerships engaged in some form of outreach activity to recruit sub-groups 'hidden' from mainstream support. In the 2018 Delivery Partner survey 28 per cent out of respondents indicated that they were specifically targeting services at particular groups of participants; (72 per cent were working with all young people). This latter proportion reflects a clear majority view amongst respondents interviewed during partnership visits that young people should not be turned away. So sub-group targeting in Talent Match was utilised more as a guide than by applying strict eligibility criteria, as might be expected in a voluntary programme. Over half of delivery partners responding to the survey reported that they specifically targeted the long-term unemployed and people with mental health issues, while very small 
numbers targeted more specific sub-groups such as refugees/ asylum seekers, gypsies and travellers, and carers - which is indicative of more targeted/ specialist support for these latter sub-groups.

In summary:

- Sub-groups targeted varied across Talent Match partnerships but there are considerable similarities in the main target groups.

- All Talent Match partnerships targeted the long-term unemployed.

- All Talent Match partnerships emphasised helping the 'hidden unemployed'.

- Talent Match has had a strong emphasis on working with young people with mental health issues.

- Generally sub-group targeting was used as a guide, rather than as an eligibility criterion for Talent Match support.

\subsection{Profile of Talent Match participants}

Not all of the target groups identified above are easily identified in survey data. However, it is possible to provide an overview of the profile of Talent Match participants. The following charts show key features of the profile of young people participating in Talent Match ${ }^{18}$ (on the basis of data from over 23,300 responses to the Common Data Framework baseline survey completed by the end December 2017) benchmarked against the population of young people not in education, employment or training (NEET), using Government surveys such as the Labour Force Survey, Understanding Society and the English Health Survey. ${ }^{19}$

\section{Gender}

\section{Talent Match}

Participants

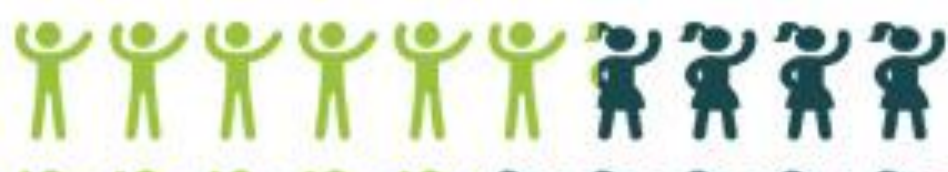

$63 \%$ male

All NEETs

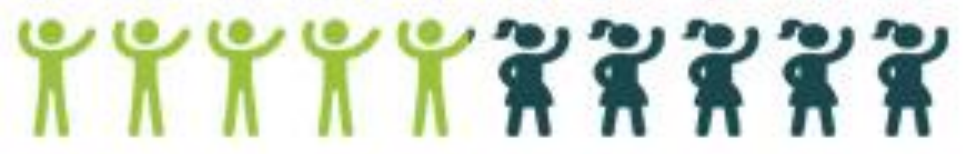

$48 \%$ male

Source and bases: Baseline survey $(23,351)$, Labour Force Survey (619)

- Almost two thirds (63 per cent) of young people participating in Talent Match are male.

- In contrast only around half (48 per cent) of all NEETs in England are male.

\footnotetext{
${ }^{18}$ Note that those 'participating' in Talent Match need not have the same profile as those targeted by Talent Match.

${ }^{19}$ Damm, C. and Sanderson, E. (2018) Who is participating in Talent Match? Sheffield: CRESR, Sheffield Hallam University.
} 


\section{Disability}

Talent Match participants

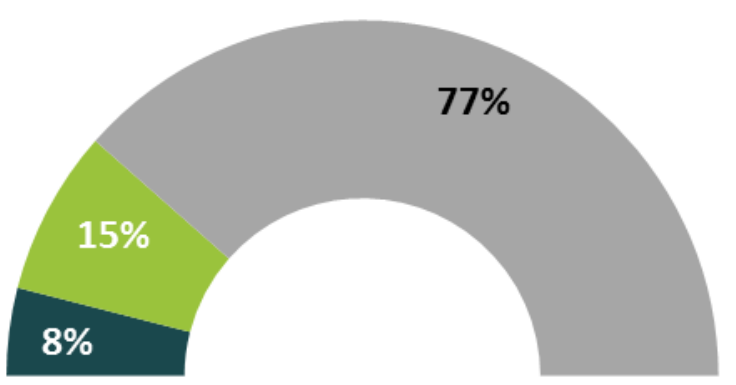

All NEETs in England

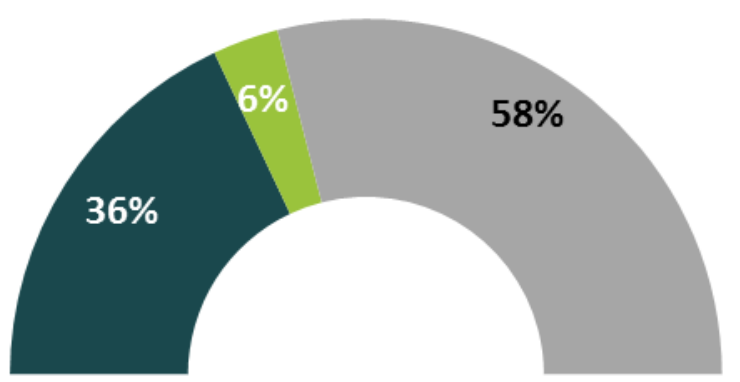

$\square$ Yes and limits activities $\square$ Yes but does not limit activities $\square$ No long term disability

Source: Baseline survey $(22,846)$, Labour Force Survey $(617)$

- Almost one quarter of Talent Match participants indicated that they have some form of disability (23 per cent). This is lower than the percentage of NEETs nationally who have a disability (42 per cent), though the national survey question is much more inclusive.

- The percentage with a limiting disability within Talent Match (8 per cent) is much lower than in the population of NEETs (36 per cent).

Talent match partnerships appear to have delivered services to fewer disabled NEETs than would be expected purely from their prevalence in the population. This may reflect particular challenges in recruiting these young people and helping them to find work. It is indicative of the wider disability employment gap in England.

\section{Parental status}

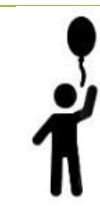

- $16 \%$ of beneficiaries overall have at least one child

- $20 \%$ of NEETs nationally have at least one child

Source: Baseline survey $(20,514 ; 21,851)$, Understanding Society (2011-13: 309, 2015-17: 599) 


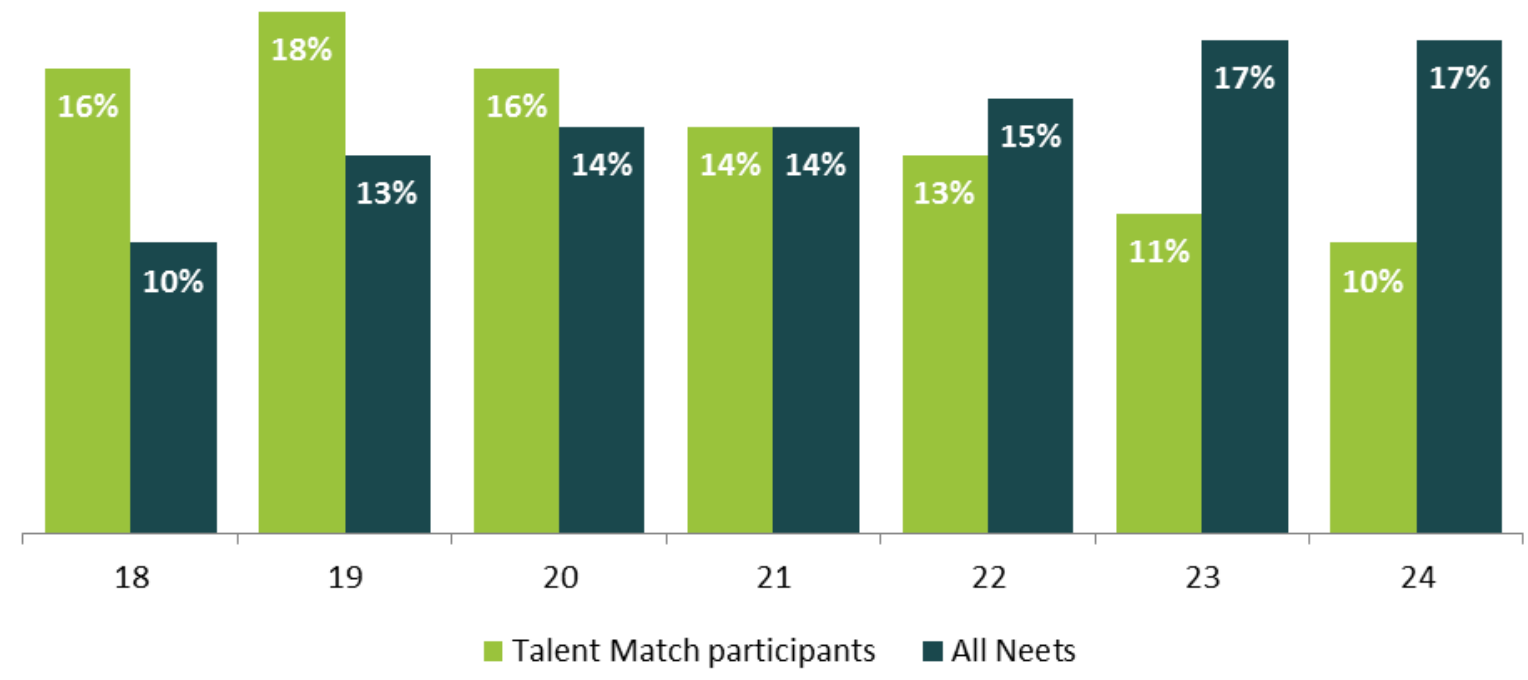

Source: Baseline survey $(23,378)$, Labour Force Survey (619)

- Half of young people signed up to Talent Match were aged 18-20 at their baseline interview.

- This suggests that Talent Match participants are on average slightly younger than NEETs across England, who are more concentrated in the 22-24 range.

\section{Ethnicity}

White English/Welsh/Scottish/Northern Irish/British/Irish
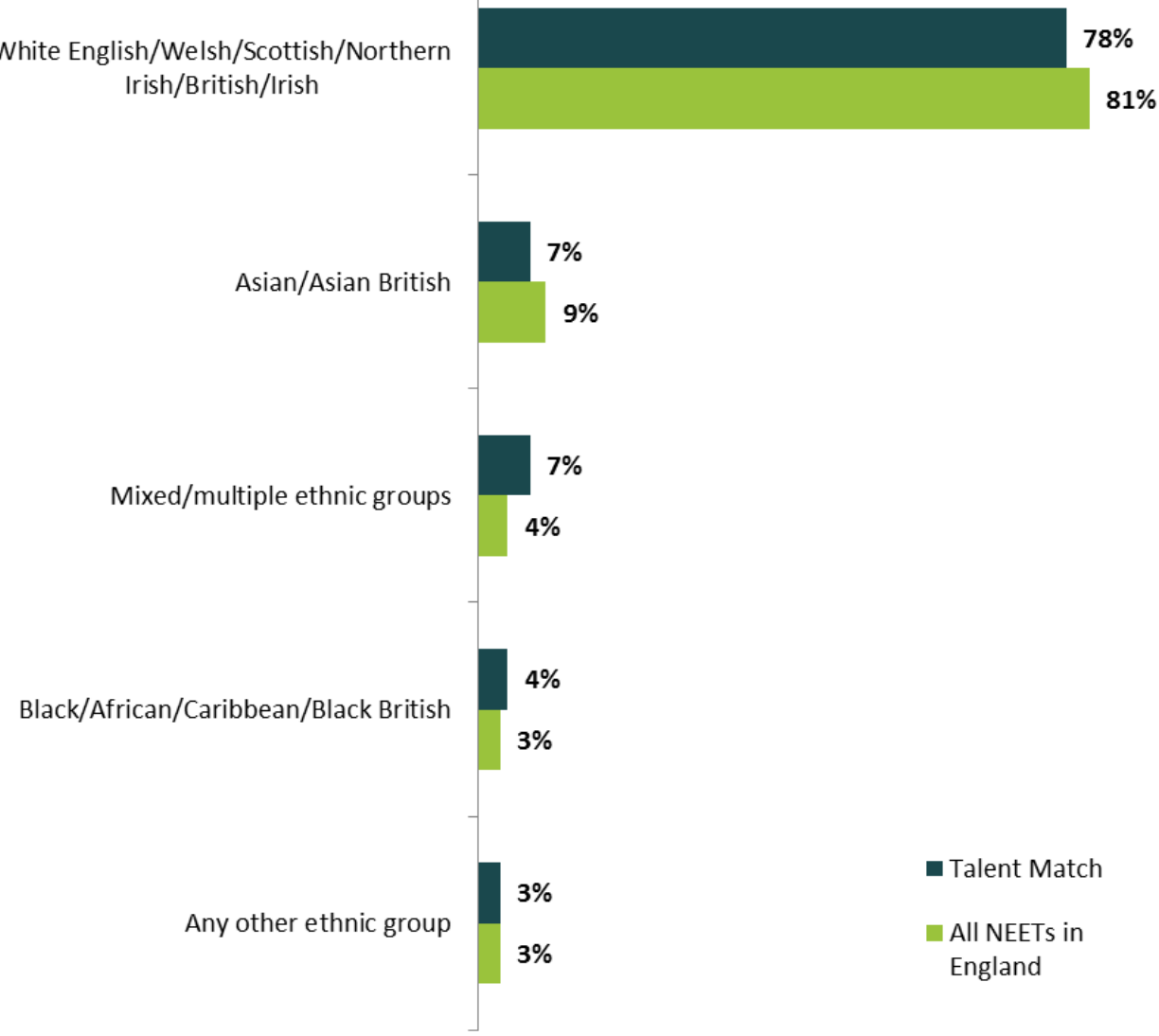

Source: Baseline survey $(21,123)$, Labour Force Survey (619) 
- 22 per cent of Talent Match participants identify as part of an ethnic-minority (all categories except for 'White British' and 'White Irish').

- This is similar to the proportion identifying as an ethnic-minority amongst all NEETs in England (19 per cent).

Maths and English

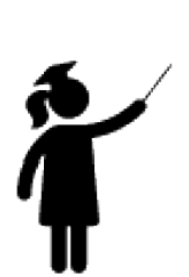

$69 \%$ had not achieved five GCSEs $A^{*}-C$ including English and Maths (or equivalent) at the baseline.

\section{This compares to $68 \%$ for all NEETs nationally}

Source: Baseline survey (22,301), Labour Force Survey (secure lab)

\section{Benefits}

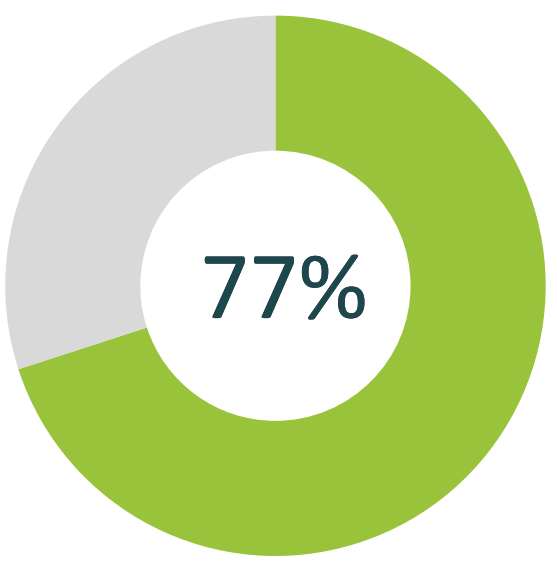

Source: Baseline survey (23,361), Labour Force Survey (619)

- $77 \%$ of Talent Match beneficiaries indicated they receive benefits. The remainder are 'hidden NEETs'.

- $57 \%$ of all NEETs in England receive benefits. 


\section{Previous experiences of employment}

38 per cent of Talent Match participants had previously held employment. This is lower than the percentage for NEETs nationally (53 per $\operatorname{cent}^{20}$ ), though this could be related to the lower average age of Talent Match participants.

\subsection{Conclusions on targeting in Talent Match}

The original focus of the programme was on geographic hotspots of youth unemployment. How this was interpreted and implemented varied, although most Talent Match partnerships did have some place-based targeting at the outset. The clear direction of travel was one of relaxation over time. While some Talent Match partnerships retained a reasonably tight focus on original hotspots, others moved increasingly to a more flexible approach which used hotspots as the focal point for delivery and the broadening of small hotspots to include larger parts of towns and conurbations, others largely abandoned place-based targeting (often after only having relatively vague place-based targeting at the outset). The driver for these changes was a combination of pragmatism in reaching the required number of participants, intelligence suggesting a wider approach was needed, the desire to maintain involvement of a wider group of partner organisations and young people's general hostility to a 'postcode lottery'.

Talent Match partnerships engaged in some degree of sub-group targeting, although the specificity of this varied between partnerships. As would be expected in a programme sensitive to local circumstances, the precise groups targeted varied to some extent across Talent Match partnerships, although there was a strong emphasis on the long-term unemployed and those 'hidden' from official statistics. Sub-group targeting helped in identifying priorities, but was not strictly enforced as an eligibility criterion. Indeed, baseline survey data and qualitative longitudinal analyses reveal that some of the young people supported by Talent Match had good formal qualifications and previous labour market experience, but perhaps had faced a 'crisis' (e.g. a health issue, being a victim of crime, loss of a job, etc.) that they needed help to cope with to 'get back on track'. With its holistic approach, Talent Match was well equipped to provide such support.

In general, Talent Match appears to have generally provided services to a cohort of young people representative of NEETs nationally. Relative to the population of NEET young people Talent Match participants were notably more likely to be male, perhaps suggesting that the Talent Match programme was particularly attractive to young men as opposed to young women and/ or that Talent Match partnerships needed to invest greater resource to recruit young women). The most marked difference between the two groups is in relation to disability. Talent Match partnerships appear to have delivered services to fewer disabled NEETs than would be expected purely from their prevalence in the population. This may reflect particular challenges in recruiting these young people and helping them to find work. It is indicative of the wider disability employment gap in England. Talent Match participants were slightly younger than NEETs nationally. Talent Match participants were also slightly less likely to be parents, less likely to have five $A^{*}-C$ GCSEs including Maths and English, and less likely to have previously held employment. All of these features might be explained in part by the fact that the age profile of Talent Match participants is more skewed towards the younger age groups than NEETs nationally. Talent Match participants were more likely to receive benefits (and so less likely to be 'hidden NEETs'). One factor explaining this could be that there were referrals to Talent

\footnotetext{
${ }^{20}$ Measured using the Labour Force Survey (base 619)
} 
Match from the Work Programme in some local partnership areas. The two groups were broadly similar in terms of their ethnicity.

The evidence from Talent Match suggests that targeting (whether by geography or sub-group) needs to be informed by a clear rationale at the outset. For a programme seeking to support innovation and based on a 'test and learn' approach, it is helpful to have greater clarity about why particular groups are being supported.

As a voluntary programme the Talent Match experience reveals a limited appetite for use of targeting as an eligibility criterion for participation. There are understandable reasons for this, but in these circumstances there is a danger that when pressures increase to achieve programme targets that recruitment to the programme and greater support moves towards those individuals more likely to achieve positive outcomes. ${ }^{21}$

\footnotetext{
${ }^{21}$ This is a process of 'creaming' and some partnership visits yielded suggestive evidence for it.
} 


\section{Understanding progression towards, into and within employment}

\subsection{Introduction}

This section starts by introducing the concept of progression and provides an overview of the existing evidence base on progression. Talent Match thematic studies on in-work support ${ }^{22}$ and key workers ${ }^{23}$ contribute to this evidence base.

Next, findings are presented on quantitative analyses of progress, focusing primarily on employment, but also on other outcomes for Talent Match participants using survey data from the Talent Match Common Data Framework which collects information from Talent Match participants at various stages of their Talent Match journey. A brief comparison with The Work Programme outcomes is also presented. The quantitative analysis is complemented by longitudinal qualitative data analyses from two rounds of interviews with a sample of young people participating in the Talent Match programme. These analyses provide a young person perspective on progression and also help place employment in a broader social context. The final discussion section reflects on the findings.

\subsection{The concept of progression}

'Progression' has a number of different meanings.

Since Talent Match is an employability programme it is appropriate to think in the first instance of progression to employment. Figure 3.1 shows a stylised pathway to employment, distinguishing between four stages: (1) pre-employment, (2) employment entry, (3) staying in work, (4) in-work progression.

\footnotetext{
${ }^{22}$ Green, A., Barnes, S-A., Gore, T. and Damm, C. (2017) In-work support: What Is the role of in-work support in a successful transition to employment?, Talent Match Case Study Theme Report. Sheffield Hallam University, University of Warwick, Big Lottery Fund. https://www4.shu.ac.uk/research/cresr/sites/shu.ac.uk/files/tm-in-worksupport-report.pdf

${ }^{23}$ Barnes, S-A., Green, A., Batty, E. and Pearson, S. (2017) Key worker models: What key worker approaches, capacity and capability are important at different stages of the journey to employment?, Talent Match Case Study Theme Report. Sheffield Hallam University, University of Warwick, Big Lottery Fund. https://blogs.shu.ac.uk/talentmatch/files/2015/03/tm-key-worker-report.pdf
} 
Figure 3.1: Stylised pathway to employment

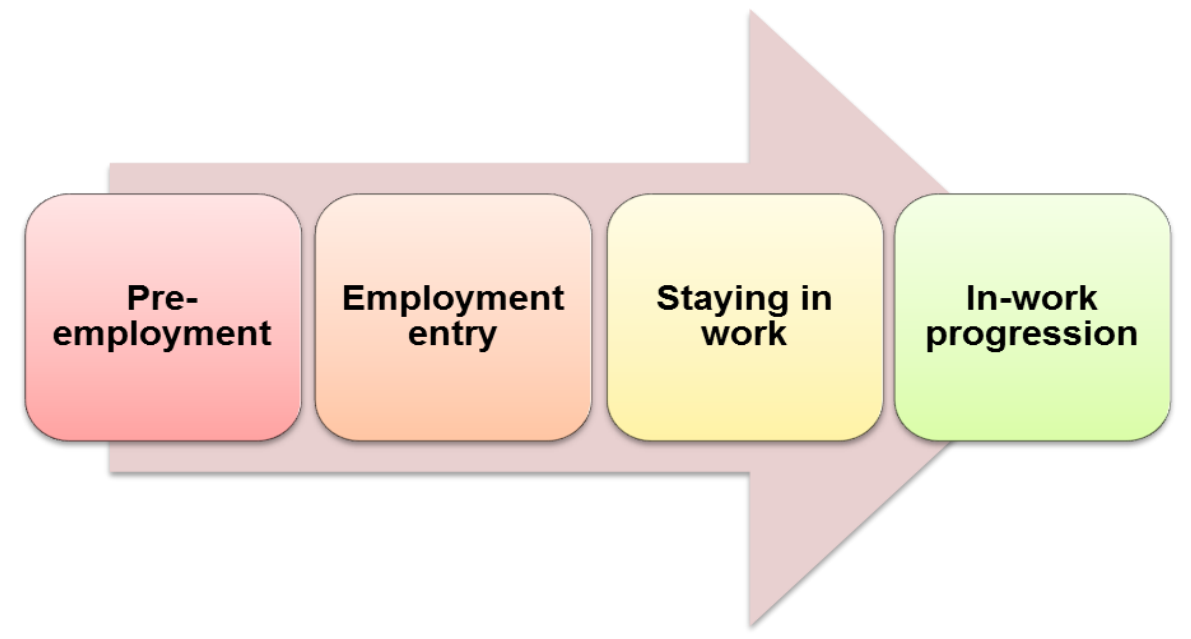

Source: adapted from Green et al. $(2015)^{24}$

Hence indicators of progression of relevance to Talent Match as an employability programme. These include:

- Engaging in pre-employment activities.

- Entering employment.

- Sustaining employment for a pre-defined time period.

- In-work progression - e.g. to a more highly paid job, to a job that better suits an individual's requirements/ ambitions, etc.

Examples of broader outcomes beyond employment which are relevant to Talent Match given that the programme adopts a broader person-centred view and so is also related to individuals' social development (which in turn might relate to progression along the employment pathway) include:

- Enhanced confidence.

- Improved well-being.

From a Talent Match participant perspective 'progression' can be measured broadly in terms of wider transitions to adulthood as well as more narrowly in relation to progress towards employment that is of direct relevance to an employability programme. It is salient to note that some Talent Match participants who engaged in longitudinal interviews highlighted improving their sense of well-being as their main priority. Others pointed to what they saw as important milestones in the transition to adulthood and independence - going beyond employment to highlight issues such as learning to drive (which could help with employment), living independently/ finding a home, and becoming financially independent. Whilst aspirations around transitions to adulthood are not always directly employment-related, they are important for two reasons. First, they can serve as a source of motivation to find work and achieve some degree of financial independence to realise life goals. Second, they can also act as stepping stones on the route into work - for example, securing stable accommodation can have a transformational effect on a person's ability to undertake paid work and/ or further study. Hence they are often indirectly related to employment.

\footnotetext{
${ }^{24}$ Green, A., Sissons, P., Broughton, K. and de Hoyos, M. with Warhurst, C. and Barnes, S-A. (2015) How cities
} can connect people in poverty with jobs. York: Joseph Rowntree Foundation. 


\subsection{What is known about progression?}

Conventionally employment support programmes have focused on preemployment and employment entry (i.e. the first two stages of the employment pathway in Figure 3.1). This is where the bulk of the existing evidence is concentrated. Yet individuals who face labour market disadvantage often need inwork support if they are to sustain employment and/ or achieve in-work progression. A key differentiating feature of Talent Match is that longer-term support is/ can be provided to a participant; in contrast to many traditional employment support programmes, provision of in-work support is feasible.

Existing evidence highlights that that careers Information, advice and guidance (IAG) is helpful in supporting people to enter, sustain and progress in employment. ${ }^{25}$ In Talent Match key workers (where they have appropriate knowledge) and employment support teams have played an important role here, alongside other labour market stakeholders. ${ }^{26}$ Evidence suggests that IAG is most effective when offered as part of an overall locally-sensitive assessment of individuals' needs alongside broader support services to overcome barriers to employment. ${ }^{27}$

The extant literature indicates that some people need support to help them with the extra costs and change of routine associated with the initial stages of the transition into employment, such as with help with transport and childcare in the first few weeks of a job. Hence flexible discretionary support can be important in helping to ease the transition between employment entry and sustaining work. It is important that this support, which may involve different areas of policy, is coordinated.

Reiterating this point about holistic and locally-sensitive support, the evidence suggests that comprehensive, individual packages of support that tailor support to an individual's needs can be particularly effective for keeping people in work, by addressing challenges that might cause them to drop out of employment. But it is difficult to find evidence on the individual activities within such a package of support to evaluate their effectiveness. Rather the evidence suggests that it is the wraparound and integrated nature of support ${ }^{28}$ and the breadth of support services that can be drawn upon at times of crisis ${ }^{29}$ that are important for employment retention. This suggests that because of its holistic, personalised and continuing nature Talent Match support to young people should be particularly wellplaced to help progression.

The quality of the initial job entry is important for keeping people in work - how the person 'fits' the job in terms of skills, suitable hours and location. This means that there is merit in helping people to get the 'right job', as opposed to 'any job'. It is notable that there is increasing policy interest in in-work progression as measured in monetary terms, particularly given the continuing roll-out of Universal Credit, but to date in the UK there has been limited attention focused on intervening in the workplace. ${ }^{30}$ In some cases financial incentives for employers to take on and retain

\footnotetext{
${ }^{25}$ Green et al. (2015) op cit.

${ }^{26}$ Barnes, S-A., Green, A., Batty, E. and Pearson, S. (2017) Key worker models: What key worker approaches, capacity and capability are important at different stages of the journey to employment?, Talent Match Case Study Theme Report. Sheffield Hallam University, University of Warwick, Big Lottery Fund. https://blogs.shu.ac.uk/talentmatch/files/2015/03/tm-key-worker-report.pdf

${ }^{27}$ Meadows, P. (2008) Local initiatives to help workless people find and keep paid work. York: Joseph Rowntree Foundation.

${ }^{28}$ Holzer, H. and Martinson, K. (2005) Can we improve job retention and advancement among low-income working parents? National Poverty Center Working Paper Series, \#05-2005.

${ }^{29}$ McQuaid, R.W., Bond, S. and Fuertes, V. (2009) Evaluation of the Working for Families Fund (2004-2008) Report to the Scottish Government.

${ }^{30}$ Sissons, P., Green, A. and Lee, N. (2016) Supporting Progression in Growth sectors: A Review of the International Evidence. Cardiff: Public Policy Institute for Wales; Sissons, P., Green A. (2017) More than a match?
} 
an individual in work for a pre-determined period can be important for stimulating employment entry and short-term retention. The experience of the Future Jobs Fund shows that wage subsidies can play a role in stimulating job entry and enabling individuals to demonstrate their employability. ${ }^{31}$

So overall, once in employment retention and in-work progression commonly depends on individuals being in the 'right job', with suitable hours, skills and location, with wraparound support which can be utilised at times of challenge/crisis (whether in work or non-work related spheres) when individuals are at risk of dropping out of employment. ${ }^{32}$ Support needs to be tailored to the individual participant and the circumstances in which they find themselves. It might be practical (e.g. provision of help with transport, suitable work-related clothing, etc.), or may take the form of advice and guidance on appropriate workplace behaviour, managing working relationships, support in thinking about next steps, etc. As emphasised in the Talent Match thematic report on in-work support, ${ }^{33}$ a supportive employer who is committed to sustaining an employees' employment helps also. More generally it is important not to overlook the role of the employer in progression towards employment-related outcomes given that employers are the gatekeepers to jobs.

Progression implies a forward/ upward trajectory. Hence it is often thought of in linear terms - e.g. as a 'ladder'. However, movement need not only be in one direction - people can move backwards as well as forwards. Also taking account of how the labour market operates and the requirements of different jobs, it may be more appropriate to conceptualise individuals' journeys towards fulfilling employment in terms of a 'climbing frame' - where moves might be forwards, backwards and across. Individuals also vary in terms of their progression ambitions ${ }^{34}$ (as revealed by qualitative and thematic analyses). Progression does not necessarily mean that movement is always forwards or upwards; there may be step downwards, backwards and sideways along the way.

Assessing the HRM challenge of engaging employers to support retention and progression. Human Resource Management Journal 27 (4), pp. 565-580.

${ }^{31}$ Fishwick, T., Lane, P. and Gardiner, L. (2011) Future Jobs Fund: An Independent National Evaluation. London: Centre for Economic and Social Inclusion.

${ }^{32}$ Green, A., Barnes, S-A., Gore, T. and Damm, C. (2017) In-work support: What Is the role of in-work support in a successful transition to employment?, Talent Match Case Study Theme Report. Sheffield Hallam University, University of Warwick, Big Lottery Fund. https://www4.shu.ac.uk/research/cresr/sites/shu.ac.uk/files/tm-in-worksupport-report.pdf

${ }^{33}$ Green, A., Barnes, S-A., Gore, T. and Damm, C. (2017) In-work support: What Is the role of in-work support in a successful transition to employment?, Talent Match Case Study Theme Report. Sheffield Hallam University, University of Warwick, Big Lottery Fund. https://www4.shu.ac.uk/research/cresr/sites/shu.ac.uk/files/tm-in-worksupport-report.pdf

${ }^{34}$ Hay, C. (2015) What do low-paid workers think would improve their working lives? York: Joseph Rowntree Foundation. 


\subsection{Findings from Talent Match quantitative analyses}

\section{Securing employment}

Analyses of data for over 23,300 Talent Match participants collected over the period to December $2017^{35}$, show that two-fifths of Talent Match participants secured (i.e. entered) employment; (the exact percentage is 41 per cent). ${ }^{36}$ The following charts show how the percentage of Talent Match participants who entered employment varies by sub-group.

Young people without a disability (limiting or non-limiting) were more likely to secure employment, compared to those with a disability. Heterosexual young people were more likely to secure employment compared to those not in this group. White young people were less likely to secure employment than those in other ethnic groups. Female young people were more likely to receive seven or more forms of support but less likely to secure employment, compared to their male counterparts (Figure 3.2).

\section{Figure 3.2: Securing employment by protected characteristics/equalities}

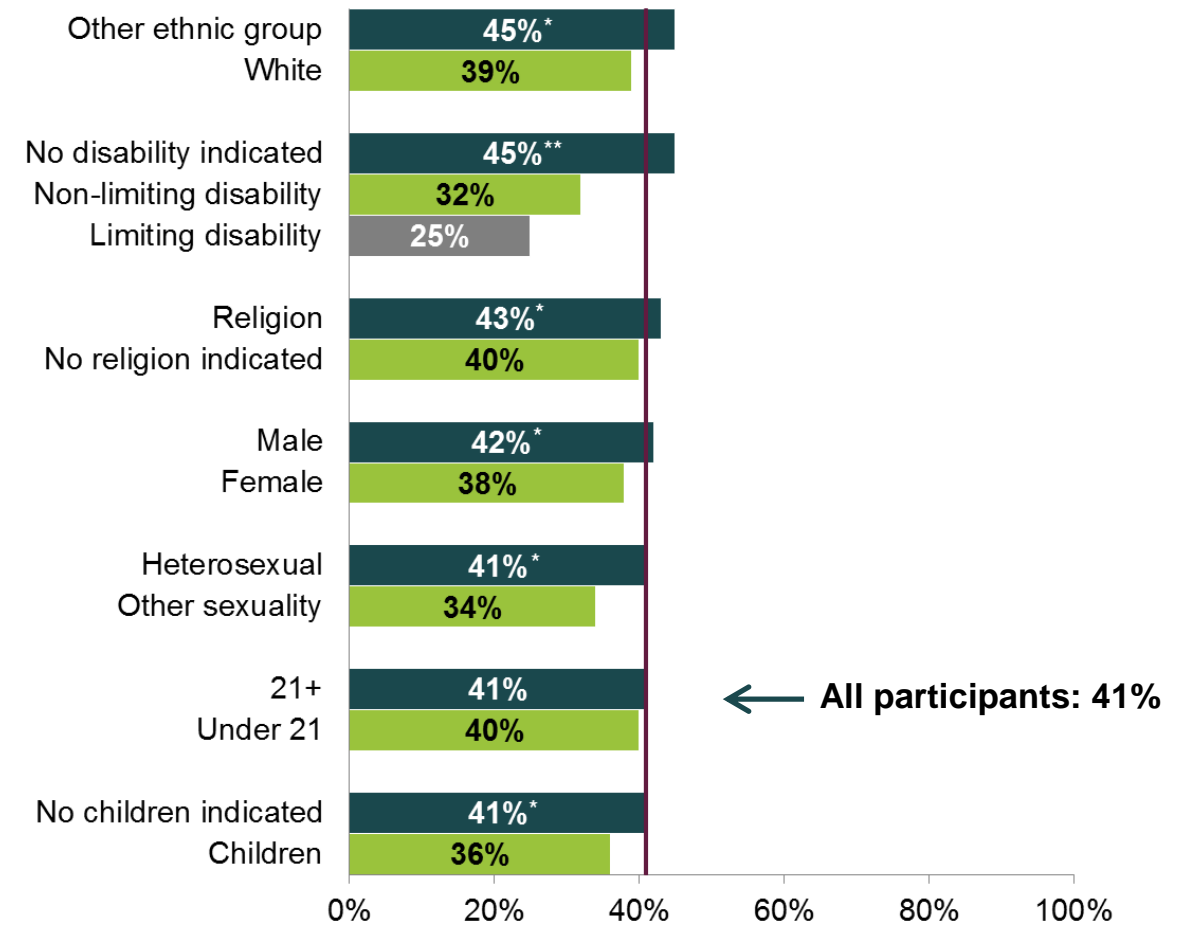

Min base: 11,346

Note: Results are based on two-sided tests with significance level 0.05 level. For each significant pair, a star appears on the bar indicating the larger proportion.

**indicates a significant difference between; no disability indicated and non-limiting disability; no disability indicated and limiting disability; and non-limiting disability and limiting disability

\footnotetext{
${ }^{35}$ The findings presented here are based on analyses of data from the Common Data Framework (CDF) which collects data from Talent Match participants from an online questionnaire on entry to the programme and then at three, six, 12, 18 and 24 months. For more detailed analyses see: Damm C. and Sanderson E. (2018) Personal characteristics and outcomes: who benefits from the Talent Match programme?, CRESR, Sheffield Hallam University.

${ }^{36}$ Defined as working 16 hours or more per week or self-employed, or working less than 16 hours per week due to commitments limiting the amount of work that they can do (e.g. caring responsibilities/ childcare commitments/ disability/ ill health/ education.
} 
Young people with five or more GCSEs at $A^{*}-C$ were also more likely to secure employment (Figure 3.3). Young people in receipt of benefits, and those who had adverse life experiences (one or more of being in the care of the local authority, a criminal conviction, alcohol or drug misuse, mental ill-health or homelessness) were less likely than those without these characteristics to secure work.

\section{Figure 3.3: Securing employment by other baseline characteristics}

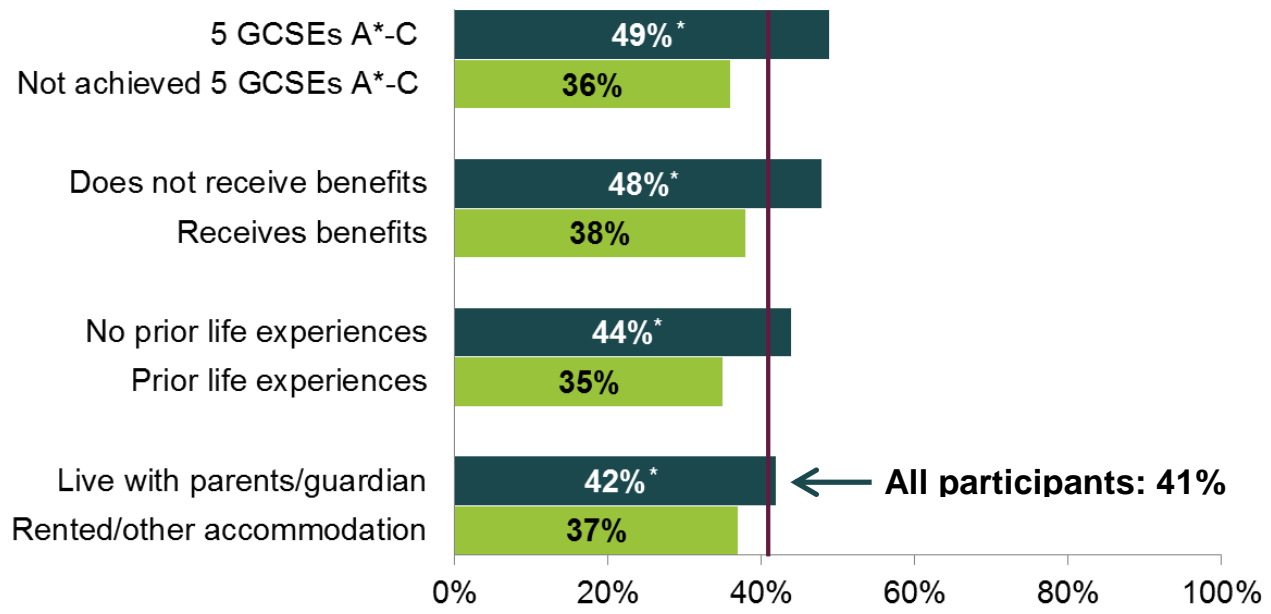

Min base: 11,329

Note: Results are based on two-sided tests with significance level 0.05 level. For each significant pair, a star appears on the bar indicating the larger proportion.

Talent Match participants who had received larger packages of support ${ }^{37}$ were more likely to secure employment than those who had received less support. Types of support positively associated with securing employment are: financial support, peer mentoring, support with travel, support addressing practical barriers, advice on personal development and information, and advice and guidance.

\section{Sustaining employment}

Nearly one-fifth of Talent Match participants sustained employment (defined as securing employment for at least six months if an employee and 12 months if selfemployed); the exact percentage is 18 per cent. Findings are similar to those relating to securing employment, in that some characteristics are associated with an increased likelihood of securing sustained employment:

- Being non-White (21 per cent, compared with 18 per cent for White).

- Not having a disability (21 per cent compared with 13 per cent with a non-limiting disability and 10 per cent with a limiting disability).

- Having higher levels of educational attainment (23 per cent for those with 5 GCSEs $A^{*}-C$ compared with 16 per cent for those who had not achieved those qualifications).

\footnotetext{
${ }^{37}$ Defined as seven or more interventions.
} 


\section{A positive role for in-work support}

The analyses of securing and sustaining employment highlight the positive role of inwork support (which is backed up by evidence from the thematic study on in-work progression). ${ }^{38}$

\section{Secondary 'hard' outcomes}

Young people are defined as achieving a secondary 'hard' outcome if they have either started or completed an apprenticeship or entered formal education and therefore appear likely to no longer be NEET for a significant period. Nearly one-fifth of Talent Match participants achieved secondary hard outcomes (the exact percentage is 18 per cent).

Characteristics associated with a greater likelihood of achieving these outcomes include:

- Being younger (22 per cent of those aged under 21 years achieved these outcomes compared with 15 per cent of those over 21 years of age).

- Not having 5 GCSEs $A^{*}-C$ prior to joining the Talent Match programme (17 per cent without such qualifications achieved a secondary hard outcome compared with 22 per cent of those who did have 5 GCSEs $A^{*}-C$ ).

- Not having applied for a job previously (20 per cent, compared with 18 per cent of those who had).

- Not having received benefits (23 per cent, compared with 17 per cent of those in receipt of benefits).

- Being in receipt of seven or more types of support (24 per cent, compared with 15 per cent of those who had received less than seven types of support).

The analyses show that previous labour market experience is less important as a factor contributing to achieving these outcomes than it is to securing and sustaining employment.

\section{Intermediate outcomes}

Young people have been defined as achieving an intermediate outcome if they have either entered a work placement or take up volunteering and have therefore taken a step towards the 'hard' outcomes above. Work placements and volunteering have been important mechanisms for supporting the progression of those Talent Match participants who were facing considerable challenges to labour market participation, potentially in the form of disadvantage or discrimination. Nearly half of Talent Match participants achieved intermediate outcomes (the exact percentage is 46 per cent). ${ }^{39}$

Characteristics associated with a greater likelihood of achieving these outcomes include:

\footnotetext{
${ }^{38}$ Green, A., Barnes, S-A., Gore, T. and Damm, C. (2017) In-work support: What Is the role of in-work support in a successful transition to employment?, Talent Match Case Study Theme Report. Sheffield Hallam University, University of Warwick, Big Lottery Fund. https://www4.shu.ac.uk/research/cresr/sites/shu.ac.uk/files/tm-in-worksupport-report.pdf

${ }^{39}$ Note that this figure may include some Talent Match participants who also went on to achieve other outcomes, including employment.
} 
- Having a disability (58 per cent of those with a non-limiting disability and 54 per cent of those with a limiting disability achieved these outcomes compared with 43 per cent of those with no disability indicated).

- Being older (49 per cent of those aged 21 years and over achieved these outcomes compared with 43 per cent of those aged under 21 years).

- Being in receipt of seven or more types of support (58 per cent, compared with 39 per cent of those who had received less than seven types of support).

- Having received peer mentoring support (59 per cent, compared with 42 per cent who had not).

- Having received information, advice and guidance (IAG) support (48 per cent, compared with 24 per cent who had not.

\section{Well-being}

Well-being is measured using the question 'Overall, how satisfied are you with your life nowadays, where nought is 'not at all satisfied' and 10 is 'completely satisfied'?' and is defined as the proportions of young people who initially recorded a 'low score' (nought to four) at the baseline stage and then went on to record a higher score at a later stage (the baseline score is compared to the latest score available). ${ }^{40}$ Over three-quarters of Talent Match participants who initially recorded a low wellbeing score went on to record a higher score at a later stage (the exact percentage is 78 per cent).

Characteristics associated with significant improvements in well-being scores include:

- Having a non-limiting disability (87 per cent, compared with 80 per cent of those reporting no disability and 72 per cent of those with a limiting disability).

- Having children (81 per cent, compared with 77 per cent for those with no children).

- Having a religion (81 per cent, compared with 78 per cent not indicating a religion).

- Having no adverse prior life experiences (83 per cent, compared with 74 per cent with adverse prior life experiences).

\section{Summary}

There are variations in progression by Talent Match sub-groups. In particular, young people from non-White ethnic groups, those without disabilities and those who have higher levels of attainment and previous labour market experiences are more likely to have achieved employment, training or apprenticeships. These are not the same groups that have received larger packages of support from the programme. Young people from White ethnic backgrounds, women and those with disabilities are less likely to achieve positive 'hard' outcomes despite having received more interventions. This could reflect other characteristics of these sub-groups or features of programme design - including the possibility that certain ingredients of support

\footnotetext{
${ }^{40}$ This analysis focuses only on those reporting a 'low' score at baseline. Those reporting a higher score at baseline have been excluded. At the time of analysis, this included 2,776 Talent Match participants.
} 
which might have helped them were absent/ not delivered in the way that would have suited them best. ${ }^{41}$

Those young people who are furthest from employment have benefited from participation in volunteering and work placements. These can be useful in helping prepare them for subsequent employment.

Participation in the Talent Match programme is associated with improvements in well-being but this is not universal. Young people with a limiting disability, those with prior adverse life experiences were less likely to report improved well-being. This may be an indication of the limitations of an employability-focused programme in addressing the overall wellbeing of young people who are most disadvantaged.

\section{A comparison of Talent Match and Work Programme outcomes}

It is possible to compare employment outcome rates for Talent Match and Work Programme participants on gender, disability and ethnicity. ${ }^{42}$ As outlined in section 2 , the Work Programme was implemented in 2011 and stopped receiving new referrals in April 2017; hence it ran over a comparable period to Talent Match. Like Talent Match, the Work Programme was focused on the longer-term unemployed, but in contrast to the grant funding, voluntary participation, primacy given to the voluntary sector and individualised and holistic support characteristics of Talent Match, the Work Programme was mandatory in nature and structured around a payment by results delivery model which arguably limited the degree of personalisation, with private sector organisations playing a lead role. Hence the programmes differ in design and ethos. It is worth noting that job outcome and sustained job outcome definitions differ between the two programmes, meaning the results are not directly comparable. Nevertheless, it is interesting to compare the findings at a broad level to observe whether the general direction of the results is consistent.

On gender Figure 3.4 shows that for sustaining a job on the Work Programme, and for all outcomes on Talent Match, a slightly lower proportion of females secured outcomes than males. The differences involved are relatively modest. On the Work Programme for job outcomes more females than males entered employment (the reverse of the position on Talent Match).

${ }^{41}$ This possible reasons are speculative and may be worthy of further investigation.

${ }^{42}$ These analyses are taken from Damm, C. (2018) Outcome comparison with the Work Programme. Sheffield:

CRESR, Sheffield Hallam University. 
Figure 3.4: Ratio of female to male job outcomes on Talent Match and the Work Programme (sustained and non-sustained)

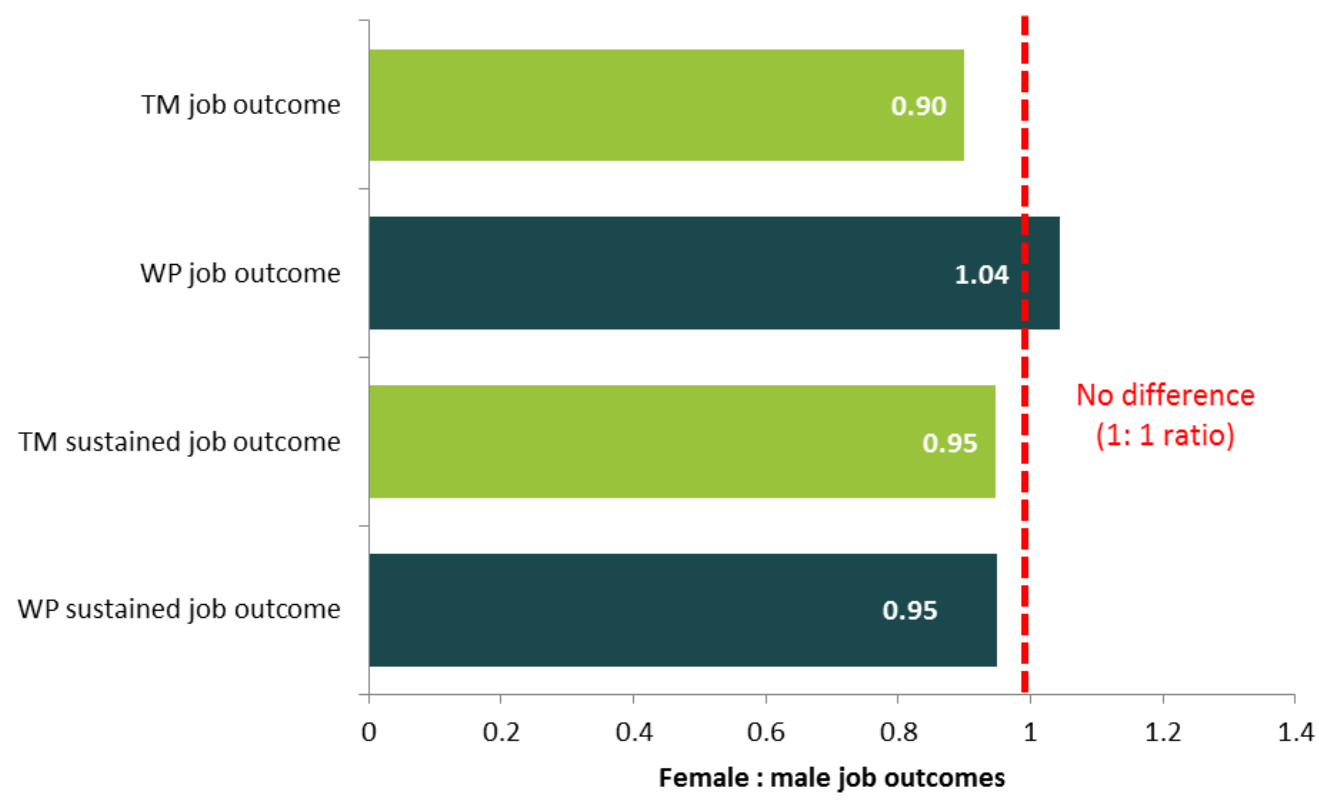

Sources and unweighted base: Stat Explore DWP data $(510,718)$, CDF Talent Match Data $(13,037)$

Figure 3.5 shows that the ratio of job outcomes for disabled participants to nondisabled is low across Talent Match and the Work Programme all the ratios are well below one (which would have indicated no difference between disabled and nondisabled participants). It is not possible to know whether both programmes were working with disabled individuals facing similar levels of disability and/ or labour market disadvantage. Rather the analyses underscore the disadvantage of disabled people in the labour market.

Figure 3.5: Ratio of disabled to non-disabled participants' job outcomes on Talent Match and the Work Programme (sustained and non-sustained)

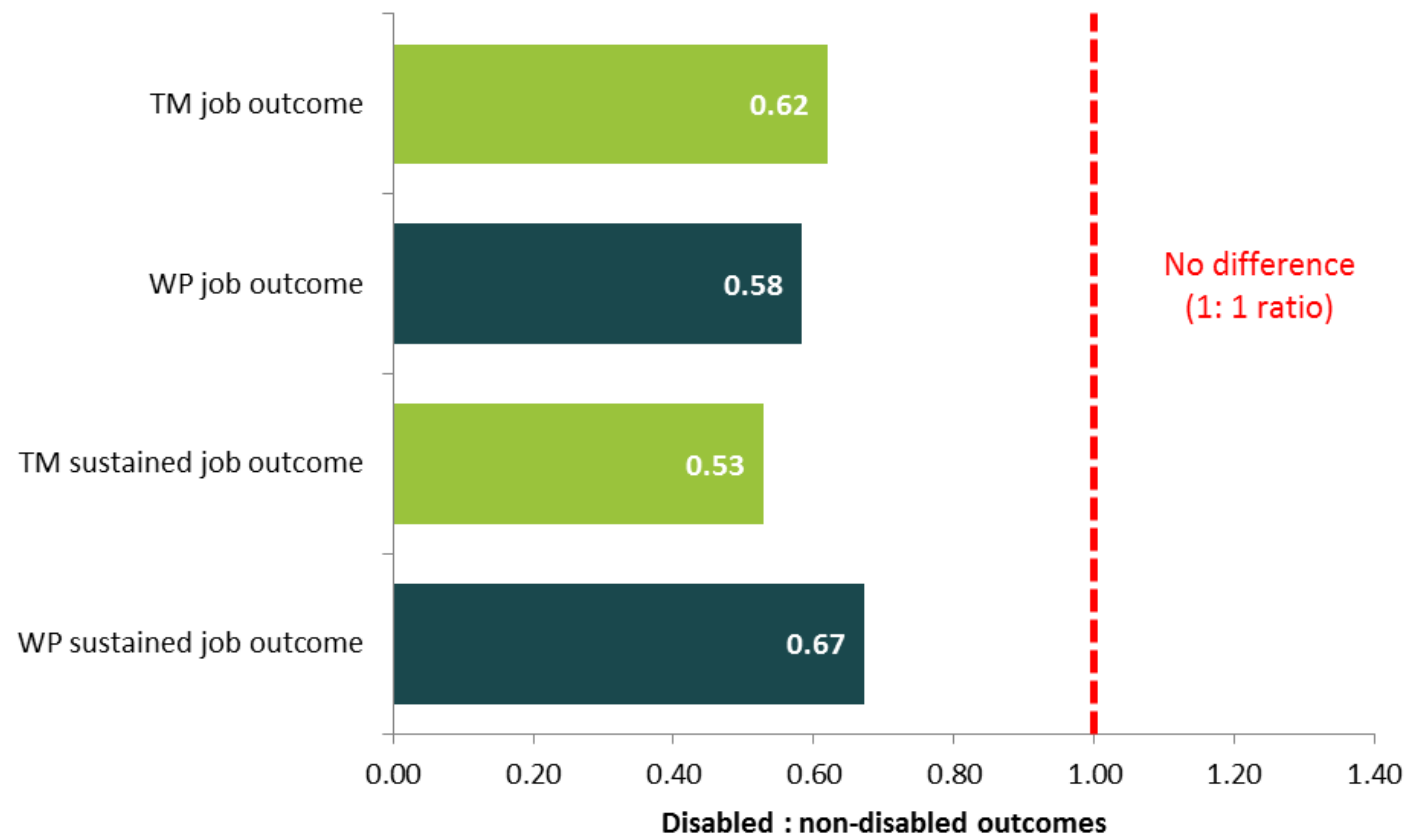

Sources and unweighted base: Stat Explore DWP data $(498,316)$, CDF Talent Match Data $(12,748)$ 
Figure 3.6 compares outcomes for Black and minority ethnic participants with White participants in the Talent Match and the Work Programme. It indicates a substantial difference between the two programmes. In contrast to the position for the Work Programme, in Talent Match a higher proportion of Black and minority ethnic participants achieve employment outcomes (including sustained outcomes) compared with White participants. This raises questions regarding whether there are differences between the profiles of non-White ethnic groups on both programmes (given considerable differences in labour market achievement between different nonWhite ethnic groups); whether ethnic minority participants on Talent Match are closer to the labour market when recruited than White participants; whether there are particular local circumstances involved (given differences in geographical coverage of the two programmes); or whether Talent Match is providing a service which works particularly well for those from ethnic minority groups in helping to overcome discrimination and other barriers to employment that are known to exist. In relation to this last point it is notable that a previous 'what works for whom' review of employment programmes ${ }^{43}$ highlighted that Black and minority ethnic groups, in particular, tended to appreciate a more 'personalised' approach with face-to-face meetings in employability programmes (i.e. the type of approach offered by Talent Match).

Figure 3.6: Ratio of Black and minority ethnic to White participants' job outcomes on Talent Match and the Work Programme (sustained and nonsustained)

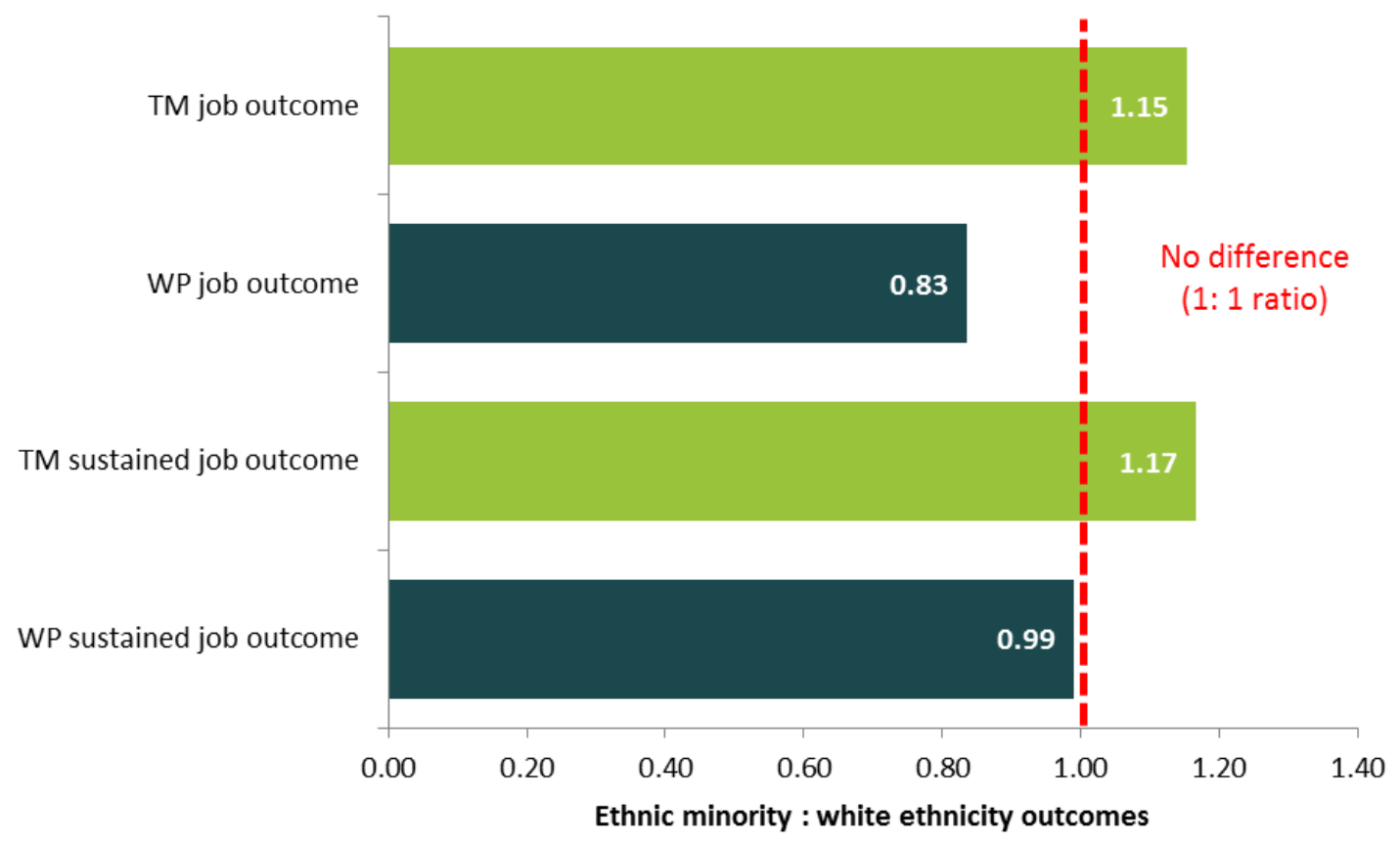

Sources and unweighted base: Stat Explore DWP data $(474,758)$, CDF Talent Match Data $(12,958)$

\footnotetext{
${ }^{43}$ Hasluck, C. and Green, A.E. (2007) What works for whom? A review of evidence and meta-analysis. Norwich: Department for Work and Pensions.
} 


\subsection{Findings from Talent Match longitudinal qualitative data analyses}

The bulk of the analyses presented in this section draw on interviews with 29 Talent Match participants between summer 2015 and spring 2017. Each Talent Match participant was interviewed twice with a gap of 12-18 months between each interview. ${ }^{44}$

For the Talent Match participants 'progress' is measured subjectively, with reference to 'hard outcomes' (such as qualification attainment, job entry, etc.), but also in relation to 'soft outcomes' (such as increasing confidence). The broader social context in which young people find themselves is important for understanding challenges to progression and how young people interpret their progress.

Talent Match participants can be divided into three broad groups in accordance with progress made in the labour market:

- Those making 'significant' progress against clear employment goals.

- Those making 'reasonable' progress in the labour market, perhaps by downgrading expectations.

- Those making 'limited or no' progress towards employment or progression in work.

These broad groups might be better thought of as clusters of positions along a spectrum as opposed to distinctive clearly definable categories. Insights into each are considered in turn below. It was also apparent that in some instances Talent Match had helped progression in terms of personal well-being, as a necessary precursor for future labour market progression.

The final sub-section discusses whether and how participants felt the Talent Match programme had contributed (or not) to their progress.

\section{Talent Match participants making 'significant' progress}

For some interviewees, significant progress had been achieved through becoming 'work ready' despite facing significant barriers. One participant with learning difficulties, for example, had secured a number of work placements through Talent Match and had also engaged in several activities though the local youth panel. This helped boost his confidence in his employability and sharpen career aspirations, and he was now looking to secure a job in administration:

\footnotetext{
${ }^{44}$ It is important to recognise that longitudinal interviews may have a bias towards young people who have more stable lives or who have made more positive progress under Talent Match as these are more likely to be contactable, and willing to be interviewed, over this time period. However, the sample of interviewees included some interviews that were ambiguous about the role of the Talent Match programme and felt it had not helped them or played only a limited role.
} 
In terms of the last year [my goals have] been made a lot clearer cos if this was me a couple of years back I wouldn't have known what I were doing, what I wanted to do, but since these placements and everything else I've got a more defined goal as to where I want to end up. So I would say it's helped tremendously, what l've been doing and how l've done it, to help me get to where I am. (Talent Match participant, Wave 2)

Other interviews have made significant progress towards achieving long-term career goals. One participant was undertaking a one year diploma to become a nursery nurse when interviewed in Wave 1 and was also contemplating applying for a university course to study to become a primary school teacher. When reinterviewed in Wave 2, she had successfully made that transition by securing a place on a teaching degree course at university that will qualify her to realise her 'dream'.

In some cases, a move into employment was not just seen as an end goal in itself but a platform on which to build a long-term career. One interviewee with an aspiration to work in business administration in Wave 1 had realised this by Wave 2 and, whilst currently enjoying the job, was also aware of how it improved her longerterm prospects, especially compared with her situation just a couple of years before:

\section{Yeah I think this jolb's definitely opened up opportunities for me...I think a lot of [my past job search activities] was just anything, retail, I was just desperate at some point, I was like I just need a job... I think if I went into job searching now l'd maybe have a better time. (Talent Match participant, Wave 2)}

Employment-related progress could also trigger change in other aspects of personal circumstances. For example, in the case of one apprentice, a shift from apprenticeship wages to the National Minimum Wage enabled a move out of unsuitable supported accommodation and this brought about a step change in their personal capacity to undertake further study alongside employment to improve chances of progression within employment.

\section{Talent Match participants making 'reasonable' progress}

Other Talent Match participants had made progress, but in this group the sense of progression was less dramatic than outlined for those considered in the previous sub-section.

In some cases the progress made had not fulfilled initial aspirations. Specifically, a handful of interviewees described failing to secure work in line with ambitions based on previous training and or education. As a result, they had been forced to downgrade expectations and look for, or take up, employment options they deemed less attractive. One interviewee who outlined aspirations in Wave 1 to find a job related to her diploma in working with animals or interests in photography had ended up lowering expectations to take up work as a barista in a coffee shop:

I hope to be somewhere different [in 12 months" time]; I don't want to be where I am, working nearly every day and doing the same thing at Costa. I would hope to go a bit more in the direction that I've been wanting to go, so more the photography. I think the past year l've just played it safe and stuck with Costa cos I did need a job so I thought I'd stick with it and see what would happen but it has been pretty much the same since last year, nothing's changed and doing the same thing every day. (Talent Match participant, Wave 2) 
One Talent Match participant expressed frustration at being unable to secure employment in IT for which they were qualified, compelling them to take up a position in the fast food sector that they did not enjoy:

\section{I wanted to do IT work... I still want to look for something else. I want a job I look forward to, instead of dreading getting up in the morning cos I've got to go to work. I don't mind working at all; I just want a job that I'm happy in. (Talent Match participant, Wave 1)}

Other interviewees who were in employment were predominantly preoccupied by their failure to find adequate hours or earn sufficient pay to achieve the independence they would like. Illustrating this situation, one participant who expressed a desire to have a full-time job and their own place in Wave 1 reflected that, when re-interviewed in Wave 2, he had achieved "two part time jobs so about a quarter of the way there". These part-time jobs in cleaning and bar work left him unable to move out of his parents' home as he could not afford local rents.

\section{Talent Match participants making limited or no progress}

Some participants reported little progress against stated goals. One interviewee with physical health problems had expressed aspirations in their Wave 1 interview to gain Maths and English qualifications that might help them to get onto a healthrelated university access course. By the point of interview in Wave 2, however, they had enrolled onto, but subsequently dropped out of, courses for English and Maths and seemed unsure about what they would to do next.

Securing work did not always feel like progress, especially if there was neither an obvious progression route within the role nor prospects of a more attractive job. One participant described feeling 'trapped' within a night-time security job which, whilst undemanding, provided little job satisfaction and no opportunities for progression:
I'm not happy with my jolb but then I need a good enough reason to leave it cos it's so easy, it might sound bad but everybody likes easy money and all I have to do is check the cameras and then play the PlayStation, but in the end I'm not going to get no satisfaction out of that...I know I want something else but it would have to be better paid anyway cos you always take more money in the end... it's a really simple job but it's not good for social life and seeing people. (Talent Match participant, Wave 1 and Wave 2)

A small minority of interviewees felt that Talent Match had not been able to help them progress. One participant looking to find a job in IT in line with qualifications gained at college felt the service had not been able to help him effectively because of a lack of understanding of specialised roles:

There was only so much they could do... They were over-selling themselves... I never got anything from any of them so it was sort of a waste of time to be honest... all they could do was try and find me IT based things ... but obviously cos they didn't know IT themselves... When I was talking to them about it, it was all just going over their heads. (Talent Match participant, Wave 2) 


\section{Attribution of progression outcomes to Talent Match}

Overall, the analyses indicate that Talent Match acted as a catalyst for progress by causing or accelerating positive change in many cases, particularly in terms of improving confidence and sense of well-being, providing inspiration and motivation to find employment, and supporting access to training and employment in practical ways.

In terms of motivation to find work, one Talent Match participant emphasised how Talent Match personalised support had a more motivating effect than interventions from Jobcentre Plus which failed to account for individual needs and circumstances:

\section{It's giving you that bit more motivation behind you so you don't feel like a robot ....cos the Jobcentre just say you're going to have to pay for [courses]. Well I can't l've got bills, l've got kids to look after, they don't take that into account, they just see you as a number. (Talent Match participant, Wave 1)}

Others reported how Talent Match had made them more inclined to look for work and had helped them 'more motivated and switched on' after rejections for sought after jobs.

Some interviews talked positively about how Talent Match support helped to develop or crystallise employment aspirations. Examples included a volunteer placement working with adults with learning difficulties organised by Talent Match which had inspired goals to work in the caring profession that the Talent Match participant had not considered previously. In another case, a work placement as a photographer within the Talent Match programme had lent credence to ambitions to work in the digital industry that the individual had previously felt unrealistic.

In terms of practical support, it was sometimes financial support that was crucial. One interviewee for whom Talent Match funded SIA training that eventually enabled him to find work in the security industry indicated that he would not have taken this step by himself given the costs of training:

\section{"I"d thought of it but I knew how much it was to get through the course" (Talent Match participant, Wave 2)}

In other instances it was raising awareness and providing support to access relevant training and employment experience opportunities that individuals might not otherwise have heard of or knew how to access was crucial. For instance:

\section{I got what I wanted from them and I always will be gratefull for that, got myself a long term job. [My adviser] helped me apply for work at [major high street retailer] I think which helped me get experience and helped in the interview to get the job where l'm at now. (Talent Match participant, Wave 2)}

Some Talent Match participants pointed to detailed bespoke practical preparation that had helped secure employment. This might involve coaching for interviews with specific employers and/ or calming pre-interview nerves not only about interview content but also about travelling to an interview.

There was also a sense among some that improvements in employability were enduring; some Talent Match participants interviewed felt that they were now in a position to find work without direct support from Talent Match. One interviewee, for 
example, spoke of how they would not need further support if they lost their job and had to look for employment again:

\section{"I guess it's a good sign really, they've made me strong enough to be independent" (Talent Match participant, Wave 2)}

Another interviewee with experience of a string of temporary jobs in factories and warehouses emphasised how his Talent Match key worker had encouraged him to look beyond temporary jobs with limited opportunities for progression and take up opportunities more in line with their longer-term aspirations:
Whenever they'd get me a job in a factory or warehouse they'd say to me it's not ideal, it's not what you want to be doing for the rest of your life. They'd always say to me there's more to you, you can achieve more... you can do something better than this....they"d try and find out what I actually what I want to do and that's how I found out that I wanted to do sales... after about my twentieth job in a warehouse and factory. I kind of need a change now and said to them about sales or retail, they got me a job in a shop in [local town] in a week. I had to go to the interview and I got it, changed jobs after about three or four months of being there, now I work in [major retailer]...so it's kind of good. (Talent Match participant, Wave 1)

The thematic study of in-work support ${ }^{45}$ highlights similar issues, as illustrated by the case study of Barry who had been sofa surfing before participating in Talent Match. The Talent Match programme paid for work-related qualifications and clothes suitable for interviews. His Talent Match key worker provided support for adapting to work routines on his entry to employment. The very committed key worker and Barry's employer worked together effectively to provide in-work and associated wraparound support for an individual who had initially been distant from employment, but it was noted that this was expensive in terms of time spent. More generally, key workers and partnership leads reiterated that in-work support might include "help with wider life" as well as dealing with work-related issues.

A significant number of Talent Match participants interviewed twice during the Talent Match programme attributed progression that they had achieved (at least in part) to Talent Match, but not all did so. Some considered that they could, and did, find employment without Talent Match. However, some interviewees in this category noted that (limited) support they had received was helpful, but that other sources of support were ultimately more important. One young man explained, for instance, how he had ambitions to "follow in [my father's] footsteps" (Talent Match participant, Wave 1) into the care sector and was able to draw on his father's advice to "open your mind to ideas" to employment options in this field. By Wave 2 he had found a job as a care worker, albeit on a zero hours contract, and was tentative about suggesting Talent Match support had helped him find the job: "I found it independently but at the same time I did get support from Talent Match just filling in the application form" (Talent Match participant, Wave 2). Crucially in this particular case, the Talent Match participant was able to draw on practical and career-related support from his family.

\footnotetext{
${ }^{45}$ Green, A., Barnes, S-A., Gore, T. and Damm, C. (2017) In-work support: What Is the role of in-work support in a successful transition to employment?, Talent Match Case Study Theme Report. Sheffield Hallam University, University of Warwick, Big Lottery Fund. https://www4.shu.ac.uk/research/cresr/sites/shu.ac.uk/files/tm-in-worksupport-report.pdf
} 


\subsection{Discussion: Talent Match and progression}

Traditionally active labour market programmes have focused on pre-employment and employment entry. Developments in policy have stimulated growing interest in progression - including sustaining employment and in-work progression (generally considered in monetary terms, but also encapsulating career development, which in turn may bring about increased financial reward). More broadly, for Talent Match participants themselves, 'progression' has a number of different meanings. It can encompass employment-related goals through to key milestones around the transition to adulthood such as securing a house/ flat, entering into a long-term relationship, becoming financially independent, and learning to drive.

Quantitative analyses show that approximately two-fifths of Talent Match participants secured employment and one-fifth of Talent Match participants sustained employment. Progression outcomes varied by Talent Match subgroups, with those from non-White ethnic groups (and for this group Talent Match outcomes were more positive than Work Programme outcomes), those without disabilities and those who have higher levels of attainment and previous labour market experiences the most likely to have achieved outcomes in employment, training or apprenticeships. Young people furthest from employment have benefited from participation in volunteering and work placements. While participation in the Talent Match programme is associated with improvements in well-being young people with a limiting disability and those with prior adverse life experiences were less likely to report improved well-being.

Qualitative analyses reveal that self-defined progress varied across Talent Match participants with some making 'significant' progress against clear employment goals; others making 'reasonable' progress in the labour market, but often only by downgrading expectations; and some making 'limited or no' progress towards employment or progression in work. Overall, Talent Match was attributed with helping progression by improving confidence and well-being, providing inspiration and motivation to find employment, and supporting access to training and employment in practical ways. A small minority of interviewees felt that Talent Match had not been able to help them progress towards employment.

Overall, the balance of evidence indicates that interviewees were more likely to suggest that Talent Match had acted as a catalyst of positive change than to reflect that support had made little or no impact upon career aspirations or progression achieved.

It is important that the role of employers is not overlooked in discussions of progression. Thematic work on employer involvement and engagement in Talent Match has emphasised how employers represent the 'demand-side' of the labour market and are gatekeepers to jobs. Hence Talent Match partnerships need to understand how their local labour market works, whether and how vacancies are advertised and employers' recruitment and selection policies to achieve their employment targets and help Talent Match participants to progress. 


\section{Conclusions}

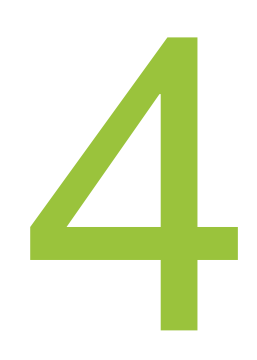

\subsection{Key findings}

This report has summarised the experiences from the Talent Match national evaluation on targeting and progression.

With regard to place-based targeting key findings emerging are that:

- Approaches to place-based targeting varied across Talent Match partnerships, with the single largest group of partnerships focusing support on geographical 'hotspots'.

- From early on in the life of the Talent Match programme place-based targeting became more relaxed. In part this reflected a decline in the number of young unemployed and so a need for expansion of target areas in order to meet recruitment targets. It also reflected a dislike amongst delivery partners, some other stakeholders and young people of eligibility for services being determined by postcode and a preference that individuals seeking support should not be turned away.

Targeting those furthest from the labour market and providing them with holistic support lay at the heart of the Talent Match programme. Key findings emerging with respect to sub-group targeting are that:

- While there was some variation in sub-groups targeted across Talent Match partnerships there are also considerable similarities in the main target groups.

- All Talent Match partnerships targeted the long-term unemployed and emphasised helping the 'hidden unemployed'.

- Most Talent Match partnerships had a strong emphasis on working with young people with mental health issues. Many also indicated that lone/ young parents were a priority group. Around half of partnerships identified individuals with low educational attainment, offenders/ ex-offenders, homeless individuals, people with physical disabilities and people with learning difficulties as sub-groups specifically targeted.

- Generally sub-group targeting was used as a guide, rather than as an eligibility criterion for Talent Match support.

- The profile of Talent Match participants shows that two in three were male (which is more than in the population of NEETs), 16 per cent were parents (slightly less than in the population of NEETs), 23 per cent had a self-reported disability (less than in the population of NEETs) and 69 per cent had not achieved five GCSEs grades $A-C$ including Maths and English before engaging in the Talent Match programme (which is more than in the population of NEETs). 
Overall, the experience of Talent Match suggests that the appetite for targeting is limited to guidance, rather than determining eligibility for support. That said, for the most part Talent Match partnerships targeted those areas and sub-groups the programme intended to target, albeit with a trend towards relaxation over time reflecting pragmatic and philosophical reasons.

Progression has a number of different meanings. It can mean progress towards and within employment - along a pathway from pre-employment to employment entry, sustained employment and in-work progression. The extant evidence base on sustained employment and in-work progression is thinner than on pre-employment and employment entry. It can also refer to broader outcomes beyond employment, such as enhanced confidence and improved well-being, which in turn may be indirectly related to employment.

Quantitative analysis on progression reveals that:

- Two-fifths of Talent Match participants secured employment and nearly one-fifth sustained employment.

- Sustaining employment was positively associated with receipt of in-work support.

- Nearly one-fifth of Talent Match participants started or completed an apprenticeship or entered full-time education, such that they would be unlikely to be NEET for a significant period.

- Nearly half of Talent Match participants entered a work placement or took up volunteering - which is likely to represent a step along the journey to employment for them.

- Young people from non-White ethnic groups, those without disabilities and those with higher levels of prior attainment were most likely to achieve positive outcomes.

- Participation in Talent Match is generally associated with improvements in wellbeing: over three-quarters of Talent Match participants who initially recorded a low well-being score went on to record a higher score at a later stage.

Qualitative analysis based on subjective measures of progression shows that:

- Some Talent Match participants considered that they made 'significant progress'. This could be by becoming 'work ready' despite facing significant barriers, making progress towards long-term career goals or moving into employment.

- Other Talent Match participants made 'reasonable progress' but the progress they made had not fulfilled initial aspirations.

- Some Talent Match participants (a minority of those interviewed on two occasions) felt that they had made little or no progress.

In general, Talent Match appears to have stimulated positive change and accelerated progress, including by improving confidence and well-being, providing motivation to find employment and supporting access to training, jobs and in-work progression in practical ways. 


\subsection{Lessons for policy makers and practitioners}

- Talent Match has made an important contribution to young people's progression: While not all positive outcomes for Talent Match participants can be directly attributed to the Talent Match programme, especially for young people with access to other positive support networks, most Talent Match participants acknowledged that the support that they had received through Talent Match partnerships was helpful in supporting them to progress toward their employment goals.

- Support for both work-related and non-work issues is needed to support young people to progress: A key part of the 'Talent Match journey' is about improved wellbeing. Evidence points to the positive impacts of an integrated package of support (which includes key worker support) in helping individuals enter, sustain and progress in work. However this support can be expensive, especially for individuals who are furthest from the labour market.

- Employers have an important role in progression: Employability programmes are often criticised for their supply-side emphasis (e.g. on the unemployed and not on employers). In any employment programme it is important to remember the role of the employer, since it is employers who are gatekeepers of jobs. For progression into employment to be achieved understanding employers' requirements and working with them, as appropriate, to support programme participants in work is beneficial. Talent Match thematic research on in-work support has provided some good examples of working with employers to secure progression. $^{46}$

- Progression is also influenced by the quality of jobs available and young people's understanding employment options. The self-assessment of young people regarding the progress that they had made highlights how some felt thwarted by unfulfilling jobs. While very few secure their dream job at the outset, the Talent Match evidence suggests that the quality of jobs is important for wellbeing and in terms of opportunities for progression. This highlights the importance of attempting to match jobs with individuals' aspirations, while also using programme support to develop an understanding of alternative job opportunities thematic research on key workers and the role of high quality information, advice and guidance shows how this might be done. ${ }^{47}$

\footnotetext{
${ }^{46}$ For further details of this research on in-work please see our thematic study. A blog is available here https://blogs.shu.ac.uk/talentmatch/blogs/?doing wp cron=1538665596.7831161022186279296875 and the longer report here: https://blogs.shu.ac.uk/talentmatch/files/2015/03/tm-in-work-support-report.pdf

${ }^{47}$ For further details of this research on the role of key workers please see our thematic study. A blog is available here https://blogs.shu.ac.uk/talentmatch/evaluation-blog-12-how-key-workers-can-help-young-people-progresstowards-work/ and the full report here https://blogs.shu.ac.uk/talentmatch/files/2015/03/tm-key-worker-report.pdf
} 


\section{Sheffield Hallam University}

\section{Talent Match Evaluation: Progression to Employment}

CRISP, Richard <http://orcid.org/0000-0002-3097-8769>, DAMM, Christopher <http://orcid.org/0000-0002-7355-3496>, GREEN, Anne, PEARSON, Sarah <http://orcid.org/0000-0001-5049-5396>, SANDERSON, Elizabeth <http://orcid.org/00000003-1423-1670> and WELLS, Peter <http://orcid.org/0000-0002-5200-4279>

Available from the Sheffield Hallam University Research Archive (SHURA) at:

http://shura.shu.ac.uk/23178/

\section{Copyright and re-use policy}

Please visit http://shura.shu.ac.uk/23178/ and http://shura.shu.ac.uk/information.html for further details about copyright and re-use permissions. 